\title{
Disruption of retinoblastoma protein function by coexpression of its C pocket fragment
}

\author{
Peter J. Welch and Jean Y.J. Wang ${ }^{1}$ \\ Department of Biology and Center for Molecular Genetics, University of California at San Diego, \\ La Jolla, California 92093-0347 USA
}

\begin{abstract}
The growth suppression function of the retinoblastoma protein $(\mathbf{R B})$ is mediated by its interaction with a variety of cellular proteins. RB contains at least two protein-binding pockets: the large $A / B$ pocket, which interacts with E2F and the D-type cyclins, and the $C$ pocket, which interacts with the nuclear c-Abl tyrosine kinase. The large $\mathrm{A} / \mathrm{B}$ pocket and the $\mathrm{C}$ pocket are shown here to be functionally distinct and can be occupied simultaneously. A complex containing E2F, RB, and c-Abl is detected in vivo and can be assembled in vitro. We propose that the biological activity of RB not only depends on the inhibition of its targets but also on its ability to properly assemble specific protein complexes. Consistent with this hypothesis, a fragment of RB, SE $\Delta$, containing only the $C$ pocket is shown to act as a dominant-negative inhibitor of RB function. SE $\Delta$ does not have growth inhibitory activity of its own. When coexpressed with full-length RB, SE $\Delta$ does not disrupt the RB-E2F or RB-D2 complexes nor does it affect the expression, phosphorylation, or nuclear tethering of the full-length RB. SE $\Delta$ does compete with RB for binding to c-Abl and is fully capable of inhibiting the c-Abl tyrosine kinase. Thus, SE $\Delta$ can inactivate RB while maintaining the inhibition of E2F and c-Abl. These results suggest that the inhibition of RB-binding proteins is not sufficient to suppress cell growth and that the assembly of RB-mediated protein complexes is also important for the promotion of cell-cycle arrest.
\end{abstract}

[Key Words: Dominant-negative mutant; E2F; cyclin D; tyrosine kinase; cell cycle]

Received August 31, 1994; revised version accepted November 15, 1994.

The retinoblastoma gene product, RB, was first identified as a suppressor of tumor formation and has since been implicated as a regulator of several cellular processes, including cell-cycle arrest, differentiation, and apoptosis. The tumor-suppressing function of RB was first suggested by the observation that homozygous loss of functional RB correlates with the development of retinoblastoma in humans (for reviews, see Hamel et al. 1993; Wang et al. 1994). Reintroduction of functional RB into $R b$-deficient retinoblastoma cells resulted in reduced tumorigenicity in nude mice (Huang et al. 1988; Bookstein et al. 1990). Loss of RB, however, does not predispose an individual to other types of cancer, such as leukemias (Hamel et al. 1993), suggesting that the tumor-suppressing function of RB is tissue specific. This is supported by observations made in mice with heterozygous disruption of the $R b-1$ gene. These $R b+/-$ mice do not develop retinoblastoma but, rather, have an unusually high incidence of pituitary tumors (Jacks et al. 1992). The biochemical mechanism by which RB suppresses tumor formation is unclear; however, it has been

${ }^{1}$ Corresponding author. suggested that $\mathrm{RB}$ inhibits tumorigenesis by inhibiting cell-cycle progression. Reintroduction of functional RB into certain $R b$-deficient tumor cell lines results in $\mathrm{G}_{1}$ arrest (Templeton et al. 1991; Hinds et al. 1992). Similar to the tumor-suppressing function, this RB-mediated growth arrest also displays cell type specificity, arresting certain tumor cells while having no effect on other cell types (Fung et al. 1993). In addition to the suppression of growth, RB has also been suggested to play a role in the proper timing and execution of cellular differentiation during development. Mouse embryos that are homozygous for mutated $R b-1$ appear to initially develop normally but do not survive past day 16 of gestation (Clarke et al. 1992; Jacks et al. 1992; Lee et al. 1992). They die without any gross morphological defects, and the loss of $\mathrm{RB}$ does not appear to affect normal cell division. Interestingly, however, death occurs with aberrant terminal differentiation of at least two tissues, namely erythrocytes and neurons, suggesting that $\mathrm{RB}$ has an essential role in the differentiation of specific cell types. Finally, $\mathrm{RB}$ has been implicated in the regulation of apoptosis. The viral oncoprotein E7 has been shown to inactivate $\mathrm{RB}$ function. When E7 is expressed in the retinas of transgenic mice, rather than developing retinoblasto- 
mas, the retina cells undergo apoptosis at a time when they normally would be undergoing terminal differentiation (Howes et al. 1994; Pan and Griep 1994). Although the biochemical mechanism underlying these various aspects of RB activity is currently unclear, these observations indicate that RB plays an interesting role, not only as a growth suppressor, but also as a key regulator of cell cycle progression and differentiation.

The RB protein is comprised of several distinct protein-binding domains (see Fig. 1) and appears to function by binding to and inhibiting the activity of a variety of cellular proteins (for review, see Wang et al. 1994). The first binding domain to be described was the $A / B$ pocket of $R B$, which has been shown to be a target for the oncoproteins of DNA tumor viruses (Hu et al. 1990; Kaelin et al. 1990). The ability of these viruses to transform cells is dependent on the ability of their viral oncoproteins to bind RB (DeCaprio et al. 1988; Whyte et al. 1988; Dyson et al. 1989; Phelps et al. 1992). It is believed that the viral oncoproteins can drive resting cells into $S$ phase by displacing cellular A/B pocket-binding proteins that are required for cell cycle progression (Chellappan et al. 1991; Helin et al. 1992; Kaelin et al. 1992; for review, see Nevins 1992). In normal, uninfected cells, cell cycle progression is thought to require the cyclical phosphorylation of RB by the cyclin-dependent kinases (cdks). The phosphorylation of $\mathrm{RB}$ also results in the release of bound cellular factors, thereby allowing S-phase entry. One set of cellular proteins that binds to the A/B pocket is the E2F family of transcription factors. E2F was first defined as a transcriptional activity that activates the E2 promoter of adenovirus and has since been found to activate a variety of $G_{1} / S$-specific genes (for review, see Nevins 1992). When E2F is bound by RB, it is transcriptionally inactive and may even function as a silencer. (Hiebert et al. 1992; Weintraub et al. 1992; Flemington et al. 1993; Helin et al. 1993). The regulated release of E2F from $\mathrm{RB}$ has been proposed to be an important step in the normal $G_{1} / S$ transition (Nevins 1992). Although this model of RB function is attractive, it is unlikely to be the whole story because the A/B pocket has been shown to interact with a variety of other cellular proteins (for review, see Wang et al. 1994)

Initially, RB-mediated protein-protein interactions appeared to occur exclusively through the A/B pocket. This was the region targeted by the viral oncoproteins as well as the location of the majority of the naturally occurring inactivating mutations (for reference, see Hamel et al. 1993). Later, however, it was found that the A/B pocket alone was unable to function as a growth suppressor. Instead, the carboxy-terminal region, outside of the A/B pocket, was also required (Huang et al. 1992;
Figure 1. Schematic representation of $\mathrm{RB}$ and c-Abl proteins. (A) Summary of RB protein fragments. Full-length RB (amino acids 1-928) is depicted at the top and contains several distinct domains: the amino-terminal domain $(\mathrm{N}$, amino acids $1-379$ ), the A/B pocket comprised of domains A (amino acids 379-572) and B (amino acids 646-772), the insert domain (ID, amino acids 572-646) and the carboxy-terminal domain (amino acids 772-928). The large A/B pocket of RB, consisting of amino acids 379-869, was defined based on its ability to interact with E2F on DNA and cause growth suppression in Saos-2 cells (Hiebert 1993). The C pocket of RB, as defined by c-Abl binding, consists of amino acids 768-869 (Welch and Wang 1993; S. Lilgegren and J.Y.J. Wang, unpubl.). RB-AE (amino acids 379928 ) is the fragment of human RB from the AseI site to the end and contains both the large $A / B$ and $C$ pockets. RB-AM (amino acids $379-834$ ) is the fragment between the AseI and MunI sites and contains the minimal $\mathrm{A} / \mathrm{B}$ pocket as defined by viral oncoprotein binding but is unable to function as a growth suppressor or interact with c-Abl. RB-AE $\Delta$ is the AE fragment with a 21-
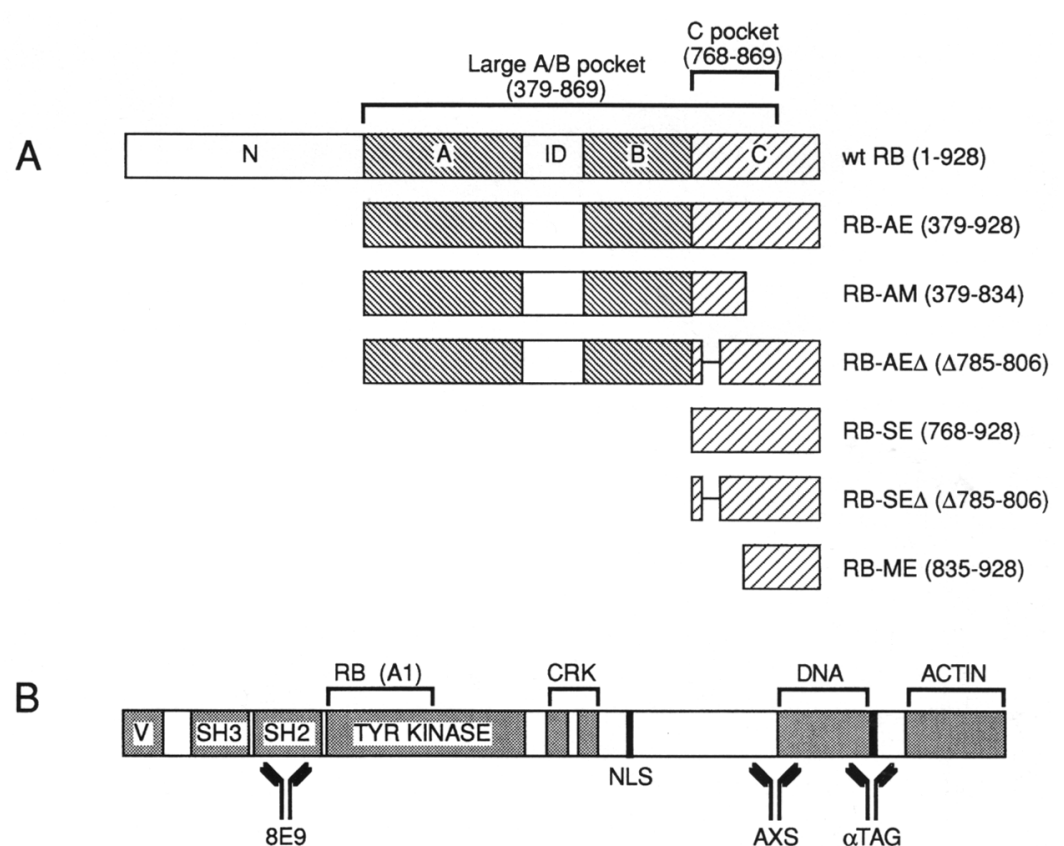

amino-acid internal deletion, rendering it incapable of growth suppression or interacting with E2F on DNA (Hiebert 1993). SE (amino acids 768-928) is the fragment of RB from the SspI site to the end and contains the entire C pocket as defined by c-Abl binding (Welch and Wang 1993). SE $\Delta$ is the SE fragment with the 21-amino-acid internal deletion described above, which can still bind c-Abl. ME (amino acids $835-928$ ) is the fragment from the MunI site to the end and is incapable of binding c-Abl. $(B) \mathrm{c}-\mathrm{Abl}$ can be divided into several different functional domains: a variable region (V) resulting from differential mRNA splicing, SH3 and SH2 (src homology) domains, a tyrosine kinase domain, and a nuclear localization signal (NLS) (for review, see Wang 1993). Binding domains for RB, CRK (Feller et al. 1994; Ren et al. 1994), DNA, and actin are also indicated. Available anti-Abl antibodies include 8E9, which recognizes the SH2 domain, AXS, raised against a 222-amino-acid stretch that includes the DNA-binding domain, and anti-TAG, which recognizes a 9-amino-acid artificially inserted epitope just carboxy-terminal to the DNA-binding domain. 
Qian et al. 1992; Qin et al. 1992; Hiebert 1993) and is the location of at least one naturally occurring mutation (Hansen et al. 1990). This led to the definition of the large A/B pocket, which contains the A/B pocket and the carboxy-terminal region up to amino acid 869 (see Fig. 1) and is fully functional as a growth suppressor. The ability of RB to bind several key cell cycle regulators, including the D-type cyclins and E2F on DNA, requires this large A/B pocket. Interestingly, the carboxy-terminal region contains another protein-binding domain, the $C$ pocket, that interacts with the c-Abl tyrosine kinase /see Fig. 1; Welch and Wang 1993). Because the carboxy-terminal region is essential, the $C$ pocket, as a distinct protein-binding domain, may be important for the biological function of RB. We had found that this $C$ pocket functions independently of the minimal A/B pocket, because RB could be shown to simultaneously bind the viral oncoprotein large $\mathrm{T}$ antigen and c-Abl (Welch and Wang 1993). At that point, however, the relationship between the large $A / B$ and $C$ pockets was unclear.

The $C$ pocket of RB was defined as the binding site for the nuclear c-Abl tyrosine kinase (see Fig. 1; Welch and Wang 1993). A ubiquitously expressed nonreceptor tyrosine kinase, c-Abl, is localized in the cytoplasm and the nucleus of both resting and actively dividing cells (for review, see Wang 1993) In the nucleus, c-Abl can bind to DNA through a unique DNA-binding domain (Kipreos and Wang 1992), which is cell cycle regulated, such that cdk phosphorylation of the DNA-binding domain abolishes its DNA-binding activity (Kipreos and Wang 1990, 1992). We have shown that the tyrosine kinase activity of the nuclear pool of c-Abl is also cell cycle regulated, as imposed by RB (Welch and Wang 1993). During quiescence and $G_{1}$, the ATP-binding lobe of c-Abl is bound by the $C$ pocket of $R B$ and the tyrosine kinase is off. As cells progress into $S$ phase, $\mathrm{RB}$ becomes phosphorylated, $\mathrm{c}-\mathrm{Abl}$ is released, and the tyrosine kinase is activated /Welch and Wang 1993). This was the first evidence for a $G_{1} / S$ activated nuclear tyrosine kinase. Furthermore, we demonstrated that the tyrosine kinase activity of nuclear c-Abl could enhance the transcriptional activity of VP16, and this supertrans-activation was inhibited by $R B$ (Welch and Wang 1993). c-Abl can processively phosphorylate the 52 tyrosine residues in the carboxy-terminal repeated domain (CTD) of RNA polymerase II (Baskaran et al. 1993). CTD phosphorylation, which also occurs on serine and threonine, is correlated with the switching of RNA polymerase from initiation to elongation mode of transcription (for review, see Dahmus and Dynan 1992). The c-Abl supertrans-activation activity may be mediated by the tyrosine phosphorylation of RNA polymerase II CTD (Wang 1994; Duyster et al. 1995).

In this report we show that the RB protein can simultaneously bind both a large A/B pocket-binding protein and a $C$ pocket-binding protein. Complexes containing $\mathrm{E} 2 \mathrm{~F}, \mathrm{RB}$, and $\mathrm{c}-\mathrm{Abl}$ can be detected in vivo and assembled on DNA in vitro, demonstrating that the $A / B$ and $C$ pockets of $R B$ are functionally distinct. We propose that $\mathrm{RB}$ is not simply an inhibitor of its binding proteins but, rather, assembles specific protein complexes in the nu- cleus to promote growth arrest. Evidence supporting this hypothesis is presented.

\section{Results \\ $R B$ can simultaneously bind $c-A b l$ and E2F}

Because the $\mathrm{C}$ pocket of $\mathrm{RB}$ is located in a region shown to be necessary for growth suppression, we wished to determine whether the $C$ pocket functioned independently of, or in concert with, the large A/B pocket to yield active $R B$. One way to address this question was to test whether the large A/B pocket could be occupied at the same time as the $C$ pocket or whether these interactions were mutually exclusive. We chose to begin this study by testing whether RB could interact simultaneously with both c-Abl and E2F on DNA.

To test all of the possible heterodimers that make up E2F activity, we used an E2F fraction that was affinity purified from exponentially growing HeLa cells /a gift from Dr. Hans Huber, Merck Research Labs, West Point, PA) and assayed its ability to form complexes with purified $\mathrm{RB}$ and $\mathrm{c}$-Abl (Fig. 2A). Functional E2F heterodimers are readily detectable in electrophoretic mobility retardation assays with a radiolabeled E2F-DNA probe. The purified E2F gave a characteristic mobility retardation pattern (lane 2), whereas neither purified c-Abl alone (lane 4) nor purified GST-RB containing intact $A / B$ and $C$ pockets (lane 3 ) gave any detectable binding to the DNA probe. When E2F was preincubated with purified $\mathrm{RB}$, the resulting $\mathrm{RB}-\mathrm{E} 2 \mathrm{~F}-\mathrm{DNA}$ complex migrated more slowly in the gel (lane 6), a supershift of the original E2F-DNA complex. When E2F and c-Ab1 were combined, no supershifted complex was detected (lane 5 ), indicating that $\mathrm{C}-\mathrm{Abl}$ could not form a stable complex with E2F. However, when both RB and c-Abl were incubated with E2F (lane 7), a complex formed on DNA that had an even slower mobility than the RB-E2F-DNA complex (cf. lanes 6 and 7), a super-supershift of the original E2F-DNA complex. This suggested that all three proteins were present in complex on the E2F DNA probe. In addition, the formation of this new complex was dependent on $\mathrm{RB}$, because $\mathrm{c}-\mathrm{Abl}$ alone had no effect on the E2F-DNA complex (lane 5).

To establish the presence of RB or c-Abl in the E2FDNA complex, several controls were performed. The viral oncoprotein E7, from human papilloma virus 16 (HPV-16), is known to disrupt the RB-E2F interaction (Huang et al. 1993; Wu et al. 1993). When purified E7 protein was included in the binding reaction containing E2F and RB, no supershifted complex was observed (lane 8 ), consistent with $\mathrm{RB}$ being responsible for the supershift (lane 6). To determine whether the added c-Abl protein was causing the super-supershift (lane 7), two antibodies directed against c-Abl were included in the binding reactions. If an antibody recognizes a protein in a shifted complex, it can either disrupt the complex or join it, resulting in a new protein complex with an even slower mobility. The anti-Abl antibody $8 \mathrm{E} 9$, which was shown previously to disrupt the $\mathrm{RB}-\mathrm{Abl}$ interaction 

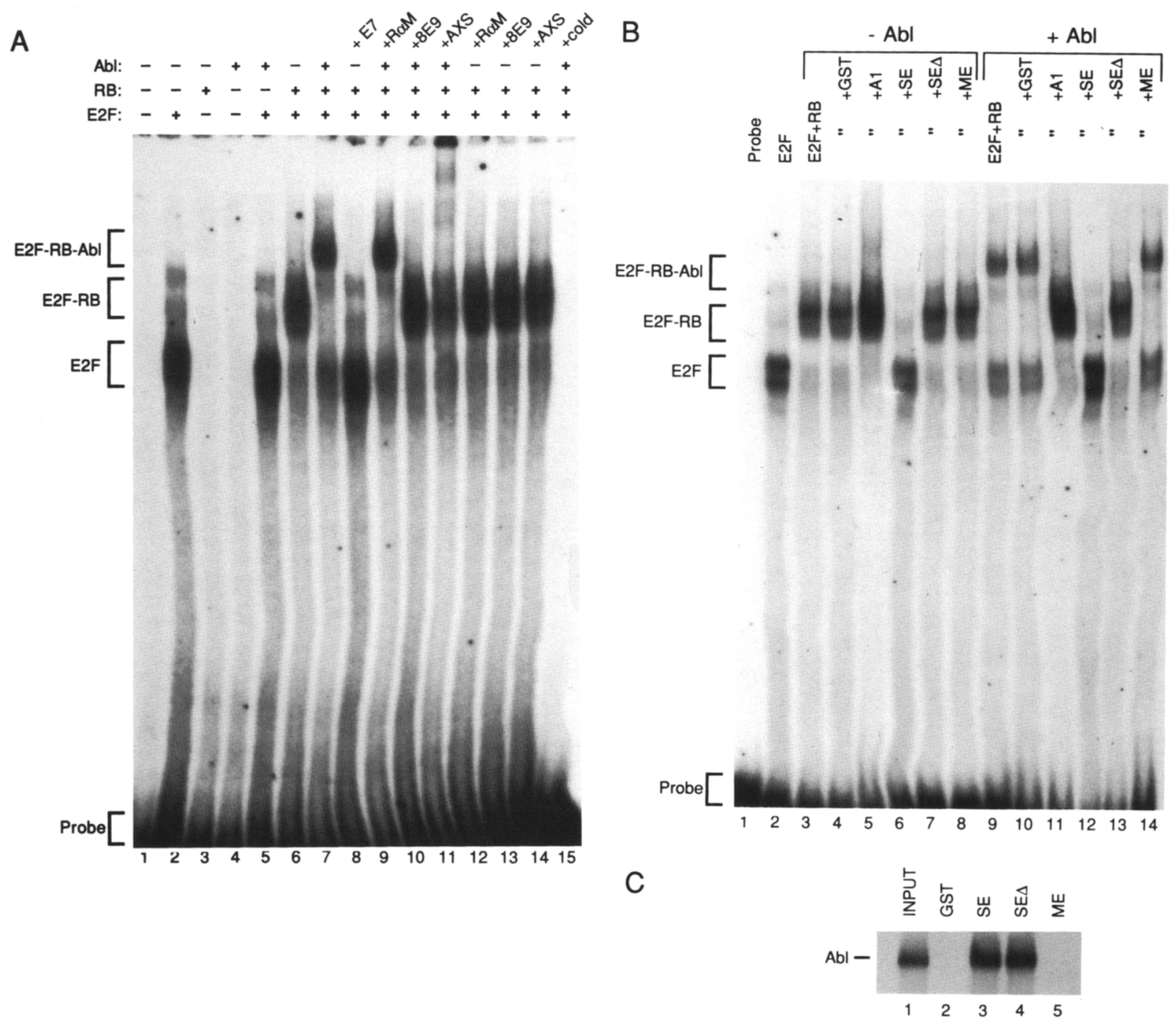

Figure 2. RB simultaneously binds to c-Abl and E2F on specific DNA. (A) c-Abl can join the RB-E2F-DNA complex. Purified E2F was incubated with purified GST-RB-AE and c-Abl purified from baculovirus-infected Sf9 insect cells, as indicated. E7 protein was purified as GST-E7 and subsequently cleaved off of the GST with thrombin (lane 8). Two different anti-Abl antibodies were added: 8E9 (lanes 10,13 ) or AXS (lanes 11,14). Rabbit anti-mouse antibody $(\operatorname{R} \alpha M$, lanes 9,12$)$ was used as a control antibody. A 100 -fold molar excess of unlabeled E2F DNA was added as a cold competitor (lane 15). The binding reactions were then analyzed by E2F mobility retardation assay (see Materials and methods). The locations in the gel of the E2F, the E2F-RB, and the E2F-RB-Abl complexes are indicated, as is the location of unbound probe at the bottom. $(B) \mathrm{Abl}$ - and RB-binding domains can disrupt the Abl-RB-E2F complex. E2F mobility retardation assay was performed with purified E2F alone (lane 2), E2F plus purified GST-RB-AE (lanes 3-8), or E2F plus purified GST-RB-AE plus purified c-Abl (lanes 9-14). Different purified protein fragments were added (prior to the addition of c-Abl) as follows: GST (lanes 4,10), Al (Abl ATP-binding lobe, amino acids 205-307, lanes 5,11), SE (RB amino acids 768-928, lanes 6,12), SE $\Delta(\Delta 785-806$, lanes 7,13), and ME (RB amino acids 835-928, lanes 8,14). (Probe; lane 1) A reaction with no purified proteins added. The locations in the gel of the E2F, the E2F-RB, and the E2F-RB-Abl complexes are indicated, as is the location of unbound probe at the bottom. $(C)$ $\mathrm{Abl}$ binds SE and SE $\Delta$ with equal affinity. In vitro-translated c-Abl was passed over glutathione-agarose beads containing $1 \mu \mathrm{g}$ of purified GST (lane 2), GST-SE (lane 3), GST-SE $\Delta$ (lane 4), or GST-ME (lane 5). Bound proteins were analyzed by $10 \%$ SDS-PAGE and visualized by fluorography.

(Welch and Wang 1993), caused a disruption of the observed super-supershift, without any effect on the RBE2F complex (lane 10). With another anti-Abl antibody (AXS), which recognizes a domain in the carboxyl terminus of $\mathrm{Abl}$, the super-supershifted Abl-RB-E2F complex migrated even slower in the gel (and even into the well; lane 11), again showing that $\mathrm{c}-\mathrm{Abl}$ was present in the complex. In the absence of added c-Abl, the anti-Abl an- tibodies did not affect the shifted complexes (cf. lanes 11 and 14), demonstrating the specificity of the antibodies in their actions. Furthermore, addition of a nonspecific antibody (lane 9) had no effect on the shifted complexes. These results show that $\mathrm{RB}$ can simultaneously bind both c-Abl and E2F-DNA, indicating that the large A/B pocket and the $C$ pocket are nonoverlapping functional domains in RB. 
Formation of the Abl-RB-E2F complex requires the large $A / B$ and $C$ pockets of $R B$

To verify that the formation of this complex was dependent on the previously defined binding domains, fragments of $\mathrm{Abl}$ or RB were tested for their ability to disrupt the shifted complexes (Fig. 2B). Again, E2F alone gave a characteristic mobility retardation pattern (lane 2), addition of RB induced a supershift (lane 3), and addition of $\mathrm{RB}$ and c-Abl caused a super-supershift (lane 9). Addition of a 10-fold molar excess of the Abl ATP-binding lobe (Al), which binds the RB C pocket, disrupted the Abl-RB-E2F complex (lane 11) but did not disrupt the RB-E2F interaction (lane 5). As a control, glutathione $S$-transferase (GST) protein purified by identical methods, had no effect on any of the shifted complexes (lanes $4,10)$. Although Al did not cause a definitive super-supershift of the RB-E2F complex, perhaps because of its small size, it did result in an apparent increase in the intensity of the RB-E2F complex, suggesting that binding of A1 may stabilize the RB-E2F-DNA complex (cf. lanes 5 and 11 with lanes 3 and 9).

Because Al was capable of preventing c-Abl from entering into the shifted complex, the $\mathrm{C}$ pocket of $\mathrm{RB}$ (Fig. $1, \mathrm{SE}$ ) would be expected to do the same. Addition of SE to the binding reaction eliminated the super-supershift (Fig. 2B, lane 12), but it also disrupted the RB-E2F interaction (lanes 6,12). Amino acids in the carboxy-terminal region of $\mathrm{RB}$ are required for the formation of a stable RB-E2F-DNA complex (Qian et al. 1992; Qin et al. 1992; Hiebert 1993). This is consistent with the ability of the SE fragment to disrupt the RB-E2F-DNA complex. However, the SE fragment alone is unable to stably bind to the E2F-DNA complex and cannot cause a supershift of the E2F-DNA band (not shown; Qin et al. 1992). It has been shown that an internal deletion in the carboxy-terminal region, $\Delta 785-806$, can prevent fulllength RB from stably binding to E2F on DNA (Hiebert 1993). This same deletion, however, does not affect the Abl-RB interaction (Fig. 2C). When an SE fragment containing this internal deletion (SE $\Delta$, Fig. 1) was included in the binding reactions, it disrupted the Abl-dependent super-supershift (Fig. 2B, lane 13), without affecting the RB-E2F complex (lane 7). An RB fragment that cannot interact with either $\mathrm{C}-\mathrm{Abl}$ or E2F (ME, Fig. 1) did not affect the Abl-RB-E2F complex (Fig. 2B, lane 14). These results showed that the formation of the Abl-RB-E2FDNA complex is mediated by the previously defined protein-binding domains and again demonstrated that the large $A / B$ and $C$ pockets of $R B$ are functionally distinct.

\section{$c-A b 1$ and E2F form an RB-dependent complex in vivo}

To determine whether RB assembles a complex containing $\mathrm{E} 2 \mathrm{~F}$ and $\mathrm{c}-\mathrm{Abl}$ in vivo, we employed a coimmunoprecipitation assay to detect $\mathrm{Abl}$-associated E2F activity (Mudryi et al. 1991). In the first experiment, we asked whether the coimmunoprecipitation of E2F with Abl was dependent on the presence of $R B$. An $R b$-deficient cell line, C33A, was transfected with RB or a tagged-Abl (see Fig. 1B) expression plasmid, either individually or in combination. Lysates of the transfected cells were immunoprecipitated with either anti-RB or anti-TAG, the monoclonal antibody 12CA5 (Niman et al. 1983) that recognizes the tagged c-Abl (see Welch and Wang 1993). The coimmunoprecipitated E2F was released by deoxycholate (DOC) and measured by electrophoretic mobility retardation analysis. A complex containing $\mathrm{RB}$ and the endogenous E2F was found in cells transfected with RB (Fig. 3, lane 8) but not with the vector plasmid (lane 7). When C33A cells were transfected with the tagged c-Abl alone, no E2F was precipitated by anti-TAG (lane 3). However, when cells were cotransfected with both RB and tagged Abl, E2F activity was detected in the antiTAG precipitates (lane 4). To demonstrate further that the coimmunoprecipitation of E2F with $\mathrm{Abl}$ depends on $\mathrm{RB}$, we transfected a mutant form of c-Abl, called AS2 (P.J. Welch and J.Y.J. Wang, in prep.), which has lost the ability to bind RB (lanes 5,6). Cotransfection of RB and tagged AS2 did not lead to the coprecipitation of E2F by

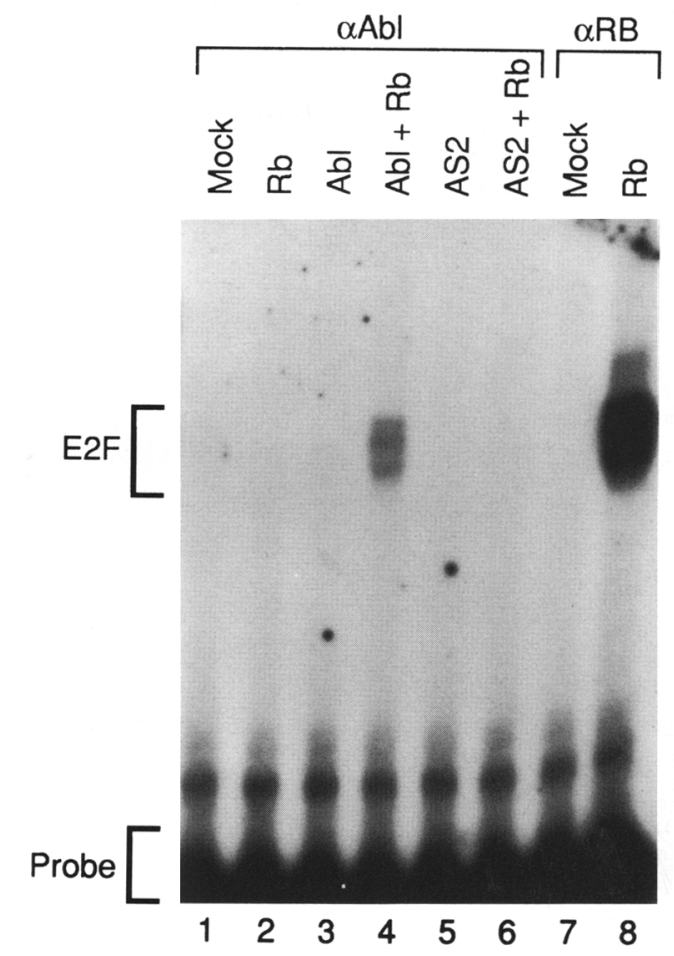

Figure 3. The Abl-RB-E2F complex forms in transfected cells. c-Abl, but not a mutant form of c-Abl, can coimmunoprecipitate E2F activity in an RB-dependent manner. C33A cells were transfected with pCMV-RB, pBK-Abl-TAG, or pBK-AS2-TAG (a mutant form of $\mathrm{c}-\mathrm{Abl}$ that can no longer bind $\mathrm{RB}$ ) as indicated. Forty-eight hours post-transfection, $500 \mu \mathrm{g}$ of total cell lysate was immunoprecipitated with either anti-TAG $(\alpha \mathrm{Abl}$, lanes 1-6) or anti-RB C36 $(\alpha \mathrm{RB}$, lanes 7,8$)$. Bound proteins were treated with DOC (to release any E2F), and the resulting supernatants were analyzed by E2F mobility retardation assay (see Materials and methods). The location on the gel of the DOCreleased free E2F is indicated, as is the location of unbound probe. 
anti-TAG (lane 6), despite similar amounts of $\mathrm{Abl}$ and AS2 being precipitated by anti-TAG (not shown). These results indicated the existence in vivo of a complex containing $\mathrm{c}-\mathrm{Abl}$ and E2F, and the formation of such a complex is dependent on the interaction of both $\mathrm{Abl}$ and $\mathrm{E} 2 \mathrm{~F}$ with RB. The amount of E2F activity brought down by anti-TAG was $\sim 5 \%$ of that coprecipitated with RB (cf. lanes 4 and 8), suggesting that not all of the intracellular $\mathrm{RB}-\mathrm{E} 2 \mathrm{~F}$ complexes contain c-Abl.

To determine whether an Abl-RB-E2F complex could also form with physiological levels of all components, we introduced Abl-TAG into a 3T3 cell line (3T3ø) derived from one of the $A b l$ knockout mouse embryos (Tybulewicz et al. 1991). This was done because our anti$\mathrm{Abl}$ antibody, 8E9, disrupts the Abl-RB complex (Welch and Wang 1993; see also Fig. 2A). Thus, we had to use a tagged version of $\mathrm{Abl}$ and the anti-TAG antibody to detect the in vivo Abl-RB complex. This also provided us with a background control, that is, 3T3ø cells containing no endogenous $\mathrm{Abl}$ protein. A stable transfectant was obtained that expressed Abl-TAG at a level slightly below that of endogenous c-Abl in regular 3T3 cells (Fig. 4B, Y.-J. Miao, unpubl.). When lysates from either the parental 3T3ø or the 3T3ø-Abl-TAG cells were immunoprecipitated with anti-RB, a similar amount of E2F activity was brought down (Fig. 4A, cf. lanes 5 and 10), and a control antibody (lanes 4,9) did not bring down any E2F activity. However, when lysates were immunoprecipitated with anti-TAG, E2F activity was only brought down from cells expressing Abl (lane 11) and not from control 3T3ø cells (lane 6). It has been reported previously that murine fibroblasts contain a very low amount of RB-E2F complex, and a majority of the E2F is in complex with the RB-related proteins, p107 and p130 (Cobrinik et al. 1993). Consistent with that report, we found that only $\sim 2 \%$ of the total E2F was coprecipitated with RB. Unlike the situation in C33A cells, the amount of E2F coprecipitated with anti-TAG was almost one-third of that brought down by anti-RB (cf. lanes 10 and 11). This is consistent with our previous observations that a high percentage of $\mathrm{Abl}$ is in complex with $\mathrm{RB}$ in $3 \mathrm{~T} 3$ cells (Welch and Wang 1993). These results established that a protein complex containing $\mathrm{c}-\mathrm{Abl}, \mathrm{RB}$, and $\mathrm{E} 2 \mathrm{~F}$ could be formed under normal physiological levels of $A b l$ and $\mathrm{RB}$; moreover, the stoichiometry of such a complex could vary widely in vivo depending on the cell type.

\section{$R B$ can simultaneously bind both $c-A b l$ and cyclin $D 2$}

Another set of cellular RB-binding proteins are the $\mathrm{D}$ family of $G_{1}$ cyclins (Dowdy et al. 1993; Ewen et al. 1993; Kato et al. 1993). The D-type cyclins can be found in complex with RB in vivo, and one functional consequence appears to be the targeting of RB for phosphorylation by the cdks during cell cycle progression. The D-type cyclins can revert an RB-induced growth arrest in Saos-2 cells (Hinds et al. 1992; Ewen et al. 1993; Zhu et al. 1993). The D-type cyclins contain the L-X-C-X-E motif found to be required in the viral oncoproteins for their interaction with RB (for review, see Wang et al. 1994).

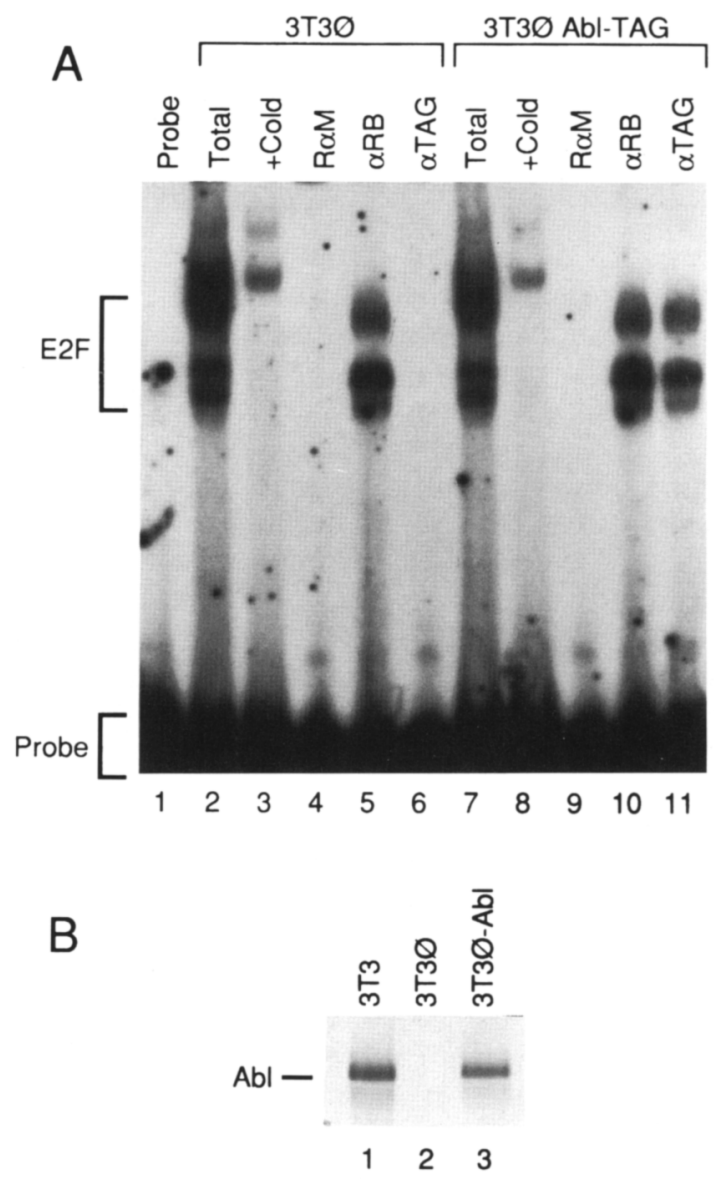

Figure 4. Abl-RB-E2F complexes are detected in vivo under physiological conditions. $(A)$ Endogenous c-Abl can coimmunoprecipitate E2F activity. Total cell lysate $(3 \mathrm{mg}$ ) from Abl knockout $3 \mathrm{~T} 3$ cells $(3 \mathrm{~T} 3 \varnothing$, lanes $2-6)$ or Abl knockout $3 \mathrm{~T} 3$ cells in which c-Abl-TAG is stably expressed (3T3ø Abl-TAG, lanes 7-11) was subjected to immunoprecipitation with rabbit antimouse $(R \alpha M$, lanes 4,9$)$, anti-RB XZ133 ( $\alpha R B$, lanes 5,10), or anti-Abl $(\alpha \mathrm{TAG}$, lanes 6,11). Bound proteins were treated with DOC (to release any E2F), and the resulting supernatants were analyzed by E2F mobility retardation assay (see Materials and methods). Total cell lysate $(15 \mu \mathrm{g})$ was also analyzed by E2F mobility retardation assay (lanes 2,7). A 100-fold molar excess of unlabeled DNA probe was used as a cold competitor (+ Cold, lanes 3,8 . The location on the gel of the DOC-released E2F is indicated, as is the location of unbound probe. $(B)$ Abl-TAG is expressed at physiological levels in the 3T3ø cells. Total cell lysate $(200 \mu \mathrm{g})$ from either normal NIH-3T3 cells (lane 1), 3T3 Abl knockout (3T3ø, lane 2), or 3T3ø-Abl reconstituted cells (lane 3) was immunoprecipitated with anti-Abl $8 \mathrm{E} 9$. Bound proteins were analyzed by $6.5 \%$ SDS-PAGE followed by anti-Abl immunoblotting.

Interestingly however, the interaction of $\mathrm{D}$-type cyclins with $\mathrm{RB}$ not only requires the $\mathrm{A} / \mathrm{B}$ pocket but also amino acids in the C pocket of RB (Ewen et al. 1993). For this reason, we wished to determine whether $\mathrm{RB}$ could simultaneously bind both c-Abl and a D-type cyclin or whether these interactions were mutually exclusive.

To address this question, the first assay was designed 
to see whether cyclin D2 could bind to immobilized GST-Al (the Abl ATP-binding lobe) in an RB-dependent manner (Fig. 5A). Full-length RB, expressed in Sf9 cells from a recombinant baculovirus, bound to $\mathrm{Al}$ (lane 6) but not GST (lane 5), as expected. Conversely, cyclin D2, also expressed in $\mathrm{Sf} 9$ cells, did not bind to $\mathrm{Al}$ above the background level (lane 3). However, when the Sf9 cells were coinfected with $R B$ and $D 2$ viruses, both $R B$ and cyclin D2 were bound to A1 (lane 8), well above the GST background (lane 7) Moreover, the presence of cyclin D2 did not affect the amount of RB bound to Al (lane 8). This result suggested that a ternary complex could form between Abl, RB, and cyclin D2 and that such a complex was mediated by RB.

To confirm this observation, a second assay was performed to test whether the RB-cyclin D2 interaction could be disrupted by protein fragments corresponding to the Abl- or RB-binding domains (Fig. 5B). Lysates from ${ }^{35} \mathrm{~S} \mid \mathrm{methionine}$-labeled Sf9 cells, infected with either $\mathrm{Abl}$ or cyclin D2 virus, were incubated with GST-RB in the presence of an excess of various unlabeled competitor proteins. The Al fragment of Abl (lane 4), but not an amino-terminal fragment (NRD, lane 3), could effectively compete for the Abl-RB interaction (Fig. 5B, top) but had no effect on the RB-D2 interaction (bottom), consistent with the results obtained in Fig. 5A. When fragments of the C pocket of RB were used (SE and SE $\Delta$, see Fig. 1), they could compete for the Abl-RB interaction but had no effect on the RB-D2 interaction (Fig. 5B, lanes 5,6). The nonfunctional ME fragment of RB (lane 7) did not affect the ability of either protein to interact with $\mathrm{RB}$. These results indicate that the $\mathrm{C}$ pocket of $\mathrm{RB}$ does not overlap with the binding site for the D-type cyclins, which accounts for the formation of a complex containing Abl, RB, and cyclin D2. It is interesting to note that the SE fragment, which can disrupt the RB-E2F-DNA complex, has no effect on the RB-D2 complex (Fig. 2B, lanes 6,12 ; Fig. 5B, lane 5). This suggests that the carboxy-terminal region may not contain any actual contact sites for D2, and its requirement for RB to bind D2 may be indirect.

\section{Two models for the molecular function of $R B$}

RB interacts with a diverse group of cellular proteins, many of which are involved in cell cycle regulation (Wang et al. 1994). The prevailing model proposes that $\mathrm{RB}$ prevents cell cycle progression by binding to and inhibiting various key proteins (Fig. 6, model 1). Because we have found that RB can bind at least two proteins simultaneously, we hypothesize that RB not only functions as an inhibitor but also as a molecular matchmaker, assembling proteins that would not otherwise interact. We propose that this matchmaking function is critical to the ability of RB to inhibit cell growth (Fig. 6, model 2).

The two models make different predictions when fulllength $R B$ is coexpressed with an individual pocket fragment (Fig. 6). The inhibitor model predicts that the large

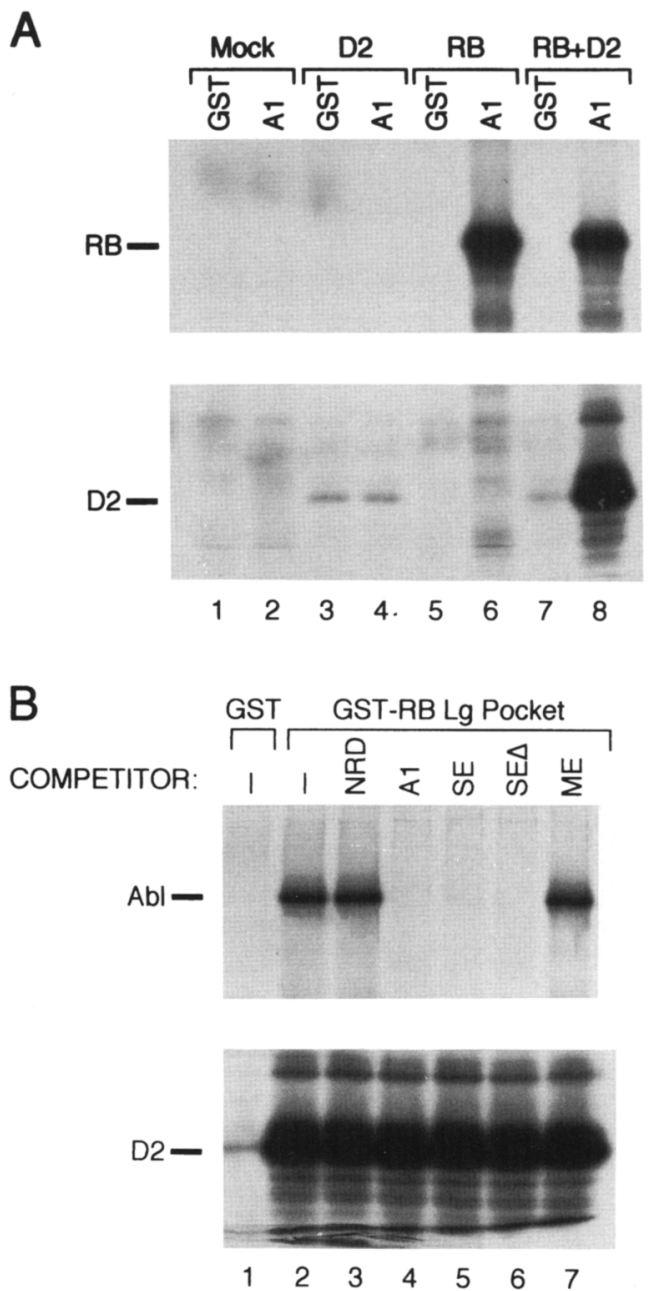

Figure 5. Formation of a trimolecular complex containing $\mathrm{c}-\mathrm{Abl}, \mathrm{RB}$, and cyclin D2. (A) RB mediates protein complex formation between c-Abl and cyclin D2. Sf9 insect cells were infected with baculovirus expressing either cyclin D2 (lar es 3,4), or RB (lanes 5,6 ), or coinfected with both cyclin D2 and RB viruses (lanes 7,8). Forty-eight hours postinfection, infected cells were metabolically labeled with $\left[{ }^{35} S\right]$ methionine for $4 \mathrm{hr}$. Detergent-free lysates were prepared and passed over glutathione-agarose beads containing $1 \mu \mathrm{g}$ of either GST or GST-A1 (Abl ATP-binding lobe, amino acids 205-307), as indicated. Bound proteins were analyzed by $10 \%$ SDS-PAGE and visualized by fluorography. $(B)$ Sf 9 insect cells were infected with baculovirus expressing either c-Abl (top) or cyclin D2 (bottom). Forty-eight hours postinfection, infected cells were metabolically labeled with $\left.{ }^{35} \mathrm{~S}\right] \mathrm{methionine}$ for $4 \mathrm{hr}$. Detergent-free lysates were prepared and passed over glutathione-agarose beads containing $1 \mu \mathrm{g}$ of either GST (lane 1) or GST-RB-AE (lanes $2-7)$. Various purified protein fragments $(5 \mu \mathrm{g})$ were included as competitors: NRD (Abl amino-terminal regulatory domain, amino acids 1-206, lane 3), Al (Abl ATP-binding lobe, amino acids 205-307, lane 4), SE (RB C pocket, amino acids 768-928, lane 5), SE $\Delta$ (RB-SE $\Delta 785-806$, lane 6), or ME (RB amino acids $835-928$, lane 7). Bound proteins were analyzed by $10 \%$ SDSPAGE and visualized by fluorography.

$\mathrm{A} / \mathrm{B}$ and $\mathrm{C}$ pockets of $\mathrm{RB}$ could function in trans; hence, the coexpression of the $\mathrm{C}$ pocket would have no effect on 
Figure 6. Two models describe RB function and the use of RB fragments to distinguish between them. For RB to suppress cell growth, it must bind and inactivate various cellular proteins, depicted as $\mathrm{Y}$ and $\mathrm{Z}$. In model 1, RB will be a functional growth suppressor as long as all binding proteins are inactivated. Therefore, coexpression of one of the proteinbinding pockets, such as the $\mathrm{C}$ pocket shown here, would not interfere with the function of RB because all of the RB-binding proteins would still be inhibited. Model 2 suggests that RB not only must bind and inhibit $\mathrm{Y}$ and $\mathrm{Z}$, but that these binding proteins must be assembled on $R B$ for $R B$ to function as a growth suppressor. If this model were correct, a C-pocket fragment would act as a dominant-negative mutant, preventing $\mathrm{RB}$ from properly assembling the binding proteins and therefore preventing $\mathrm{RB}$ from functioning as a growth suppressor.

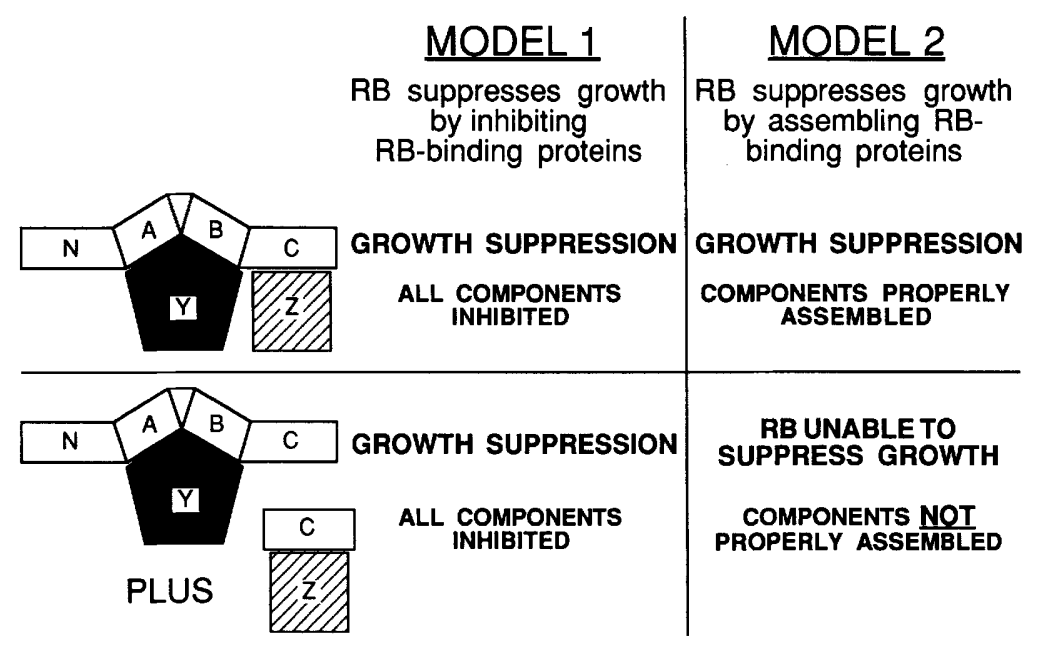

the ability of RB to inhibit growth (Fig. 6, model 1). The matchmaker model, however, predicts that the large A/B and $C$ pockets have to work in cis. Coexpression of the $C$ pocket would be expected to sequester c-Abl and possibly other $C$ pocket-binding proteins, and prevent the proper assembly of RB-mediated complexes (Fig. 6, model 2). This model predicts that the growth-suppression function of $\mathrm{RB}$ could be disrupted even when RBbinding proteins, such as $\mathrm{E} 2 \mathrm{~F}$ and $\mathrm{c}-\mathrm{Abl}$, are inhibited.

\section{The growth-suppressing function of $R B$ is inhibited by the $C$-pocket fragment}

To test the two models, we used the human osteosarcoma cell line Saos-2. These cells, which express a nonfunctional cytoplasmic form of RB, are exquisitely sensitive to the growth-suppression activity of $R B$. When functional $\mathrm{RB}$ is introduced by transfection or microin- jection, the cells become arrested in $\mathrm{G}_{1}$ but continue to grow in size, resulting in single, flat cells that can get as large as a small colony (Templeton et al. 1991; Qin et al. 1992). Similarly, we found that transfection of an RB expression plasmid into Saos- 2 cells resulted in the formation of a significant number of flat cells (Fig. 7A). When the carboxy-terminal fragment (SE) of RB was cotransfected with full-length $\mathrm{RB}$, the number of flat cells was reduced to background levels ( $+\mathrm{SE}$, Fig. 7A), indicating an interference with the activity of full-length $\mathrm{RB}$. Immunoblot analysis indicated that the SE fragment was expressed at a three- to fivefold molar excess over wild-type RB in the transfected cells (not shown). The SE fragment by itself did not cause any detectable changes in Saos-2 cell growth or morphology. Thus, the SE fragment appeared to act as a dominant-negative mutant, because it interfered with the function of wild-type $R B$ yet had no function on its own. With the same reasoning,
Figure 7. Dominant-negative fragments revert $\mathrm{RB}$-dependent growth suppression. (A) Saos- 2 cells $\left(2 \times 10^{6}\right)$ were transfected with empty vector (Mock) or vector expressing full-length RB. Certain RB-transfected plates were cotransfected with a fivefold molar excess of individual RB domains: SE (amino acids 768-928), SE $\Delta$ ( $\Delta 785-806)$, ME (amino acids 835-928), or AM (amino acids 379-834). All transfections included a puromycin resistance plasmid. Cells were selected in puromycin for 7 days, and the resulting flat $\left(G_{1} / S\right.$ arrested $)$ cells were counted. All four RB fragments were expressed at similar levels in the transfected cells, as determined by immunoblotting (not shown). (B) The dominantnegative effect is dosage dependent. Saos-2 cells $\left(2 \times 10^{6}\right)$ were transfected with full-
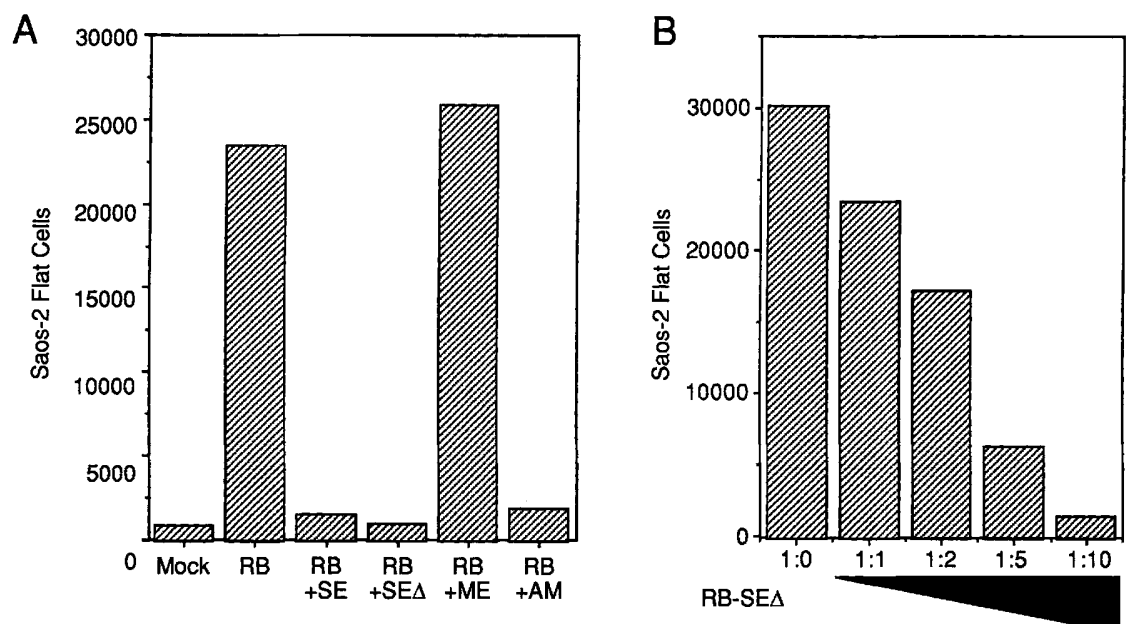

length RB and various amounts of the dominant-negative fragment SE $\Delta$. The ratio of full-length RB/RB-SE $\Delta$ varied from 1:0, 1:1, 1:2, 1:5 and 1:10. All transfections included a puromycin-resistance plasmid. Cells were selected in puromycin for 7 days, and the resulting flat $\left(G_{1} / S\right.$ arrested $)$ cells were counted. 
the $A$ /B pocket of $R B$ should also function as a dominant-negative mutant. When an $A / B$ pocket fragment was cotransfected with full-length $R B$, the number of $\mathrm{G}_{1}$-arrested flat cells was again reduced to background levels (+AM, Fig. 7A). This fragment contains only the minimal A/B pocket (see Fig. 1) and is unable to cause growth suppression on its own (Huang et al. 1992; Qin et al. 1992). Although both the A/B and carboxy-terminal fragments function by binding and inhibiting cellular proteins, they are unable to work in trans, that is, expression of SE with AM does not give rise to any flat cells (not shown; Qin et al. 1992).

Because the SE fragment could disrupt the interaction of RB and E2F on DNA (see Fig. 2B, lanes 6,12), it was possible that $S E$ was preventing the $G_{1} / S$ block by causing the release of E2F bound by the full-length RB. To rule out that possibility, we used the SE $\Delta$ fragment of RB that contained an intact $C$ pocket but did not disrupt the RB-E2F or the RB-D2 interaction (Figs. 2B and 5B). Despite the inability of SE $\Delta$ to interfere with the binding of RB to E2F-DNA or to cyclin D2, this C pocket fragment caused a reduction in the number of $G_{1}$-arrested flat cells when coexpressed with the full-length $\mathrm{RB} \mid+\mathrm{SE} \Delta$, Fig. 7A). This result showed that RB function could be inactivated by C-pocket fragment that did not release E2F or cyclins. This dominant-negative inhibition of RB required at least one functional protein-binding pocket because the ME fragment of $R B$, which has no known protein-binding activity, had no effect on the number of RB-induced flat cells (+ME, Fig. 7A).

If the $\mathrm{C}$ pocket fragment was acting by competing with the full-length RB for binding to c-Abl, then its effect should be concentration dependent. To test this, Saos-2 cells were transfected with $\mathrm{RB}$ and varying amounts of the SE $\Delta$ expression plasmids (Fig. 7B). As predicted, the inhibitory effect of SE $\Delta$ was dosage dependent because the number of flat cells decreased with increasing amounts of SE $\Delta$ DNA (Fig. 7B). The current data cannot rule out the formal possibility that SE $\Delta$ may disrupt the binding of an as-yet-unidentified protein that requires both the large $A / B$ and $C$ pockets to associate with RB. Nevertheless, the data are consistent with the proposal that the large A/B and the C pockets of RB have to function in cis to suppress cell proliferation.

\section{Neither E2F nor $c-A b l$ is activated}

by the RB-SED mutant

An important prediction of model 2 is that coexpression of RB with the SE $\Delta$ fragment would not relieve E2F or $\mathrm{c}-\mathrm{Abl}$ from RB-mediated inhibition. The endogenous E2F should be inhibited by the full-length $\mathrm{RB}$, and the endogenous $\mathrm{C}-\mathrm{Abl}$ by the excess SE $\Delta$ fragment. To demonstrate that $\mathrm{E} 2 \mathrm{~F}$ and $\mathrm{c}-\mathrm{Abl}$ were still inhibited in cells expressing $\mathrm{RB}$ and SE $\Delta$, we measured their activities (Fig. 8). E2F activity, as measured by the expression of E2-CAT in Saos- 2 cells, was inhibited by full-length RB (Fig. 8A, cf. lanes 2 and 3), as described previously (for review, see Nevins 1992). When the dominant-negative fragment SE $\Delta$ was coexpressed with RB, E2F remained inhibi ad (lane 4), consistent with the observation that $\operatorname{SE} \Delta$ was unable to disrupt the RB-E2F complex (see Fig. 2B). Conversely, the SE $\Delta$ fragment would be expected to disrupt the interaction of c-Abl with full-length $\mathrm{RB}$, because SE $\Delta$ contains a functional $C$ pocket and could remove $A b l$ from the Abl-RB-E2F-DNA complex (Fig. 2B, lane 13). This was confirmed by the observation that both $\mathrm{SE}$ and $\mathrm{SE} \Delta$, but not ME, could prevent the coimmunoprecipitation of endogenous C-Abl with RB (Fig. 8C, top). However, SE $\Delta$ is fully capable of inhibiting c-Abl tyrosine kinase activity in vitro (not shown) and would therefore be expected to keep $\mathrm{Abl}$ inactive in the cotransfections. To test this, Saos- 2 cells were cotransfected with AblTAG and different RB fragments, and the activity of the nuclear pool of c-Abl was analyzed (Fig. 8B). As described previously (Welch and Wang 1993), full-length RB inhibited the activity of nuclear c-Abl (cf. lanes 2 and 5). When dominant-negative SE $\Delta$, but not ME, was cotransfected with c-Abl, the activity of nuclear c-Abl was inhibited (lanes 3,4 ) and remained inhibited in the presence of SE $\Delta$ and RB (lane 8). Together, these results allowed us to conclude that the inactivation of RB function by the SE $\Delta$ fragment was not attributable to the release or activation of either E2F or c-Abl. This is consistent with model 2, which proposes that proper RB function is not only dependent on the inhibition of its binding proteins but also on proper protein complex assembly (see Fig. 6).

\section{$R B-S E \Delta$ does not affect $R B$ phosphorylation or nuclear tethering}

When wild-type RB is expressed in Saos- 2 cells, it is completely unphosphorylated, and phosphorylation by the coexpression of cyclin A is correlated with a reversal of growth arrest (Hinds et al. 1992). The dominant-negative mutants could somehow activate RB phosphorylation, thereby reverting the $G_{1}$-arrest phenotype. To test this possibility, the phosphorylation state of RB was examined and a cotransfection with cyclin A was used as a positive control (Fig. 8C). Coexpression of any of the dominant-negative fragments had no effect on the phosphorylation state of RB (Fig. 8C, bottom, lanes 2-4), whereas cyclin A induced RB phosphorylation (lane 5), as observed previously (Hinds et al. 1992). Therefore, these data indicate that the dominant-negative mutants were inactivating $\mathrm{RB}$ function by a mechanism other than RB phosphorylation.

Several reports have indicated that $\mathrm{RB}$ can function as a growth suppressor only when properly tethered to the nucleus (Mittnacht and Weinberg 1991; Templeton et al. 1991; Alberts et al. 1993; Zacksenhaus et al. 1993; Mittnacht et al. 1994). The RB protein is always nuclear; however, the active, hypophosphorylated form of RB is more tightly associated with the nuclear structure than is the inactive, hyperphosphorylated form (Mittnacht and Weinberg 1991). During normal cell cycle progression, phosphorylation results in the untethering of RB, which is correlated with the inactivation of its growthsuppressing function (Mittnacht and Weinberg 1991; Hinds et al. 1992; Templeton 1992; Alberts et al. 1993). 
Figure 8. The dominant-negative fragments do not activate c-Abl or E2F nor do they affect $R B$ phosphorylation or nuclear tethering. $(A) \mathrm{E} 2 \mathrm{~F}$ remains inactive in the presence of the dominant-negative mutants. Saos- 2 cells were cotransfected with the E2-CAT reporter, $\mathrm{PCMV}-\mathrm{RB}$, and $\mathrm{RB}-$ $\mathrm{SE} \Delta$ as indicated. Forty-eight hours posttransfection, CAT assays were performed on total cell lysates. Values represent the average percent acetylation of $\left[{ }^{14} \mathrm{C}\right] \mathrm{chlo}$ ramphenicol, normalized to $\beta$-galactosidase activity. (B) Nuclear c-Abl remains inactivated in the presence of the dominant-negative mutants. Saos- 2 cells were cotransfected with Abl-TAG (lanes 2-5,7,8) and either SE $\Delta$ (lane 3), ME (lane 4), full-length RB (lane 5) or both SE $\Delta$ and full-length RB (lane 8). Forty-eight hours post-transfection, cells were fractionated and nuclear lysates were immunoprecipitated with anti-TAG antibody. Bound proteins were analyzed for $\mathrm{Abl}$ kinase activity (top) or anti-Abl immunoblotting (bottom). (C) The dominant-negative mutants disrupt the in vivo RB-Abl complex but do not affect the expression or phosphorylation state of RB. Saos- 2 cells were cotransfected with pCMV-RB and the following dominant-negative fragments: SE (lane 2),

SE $\Delta$ (lane 3), or ME (lane 4). One plate was cotransfected with cyclin A (lane 5), as a positive control for RB phosphorylation. Forty-eight hours post-transfection, cell lysates were immunoprecipitated with anti-RB antibody. Bound proteins were separated by $6.5 \%$ SDSPAGE and analyzed by anti-Abl (top) or anti-RB immunoblotting. Abl, phosphorylated RB (ppRB), and unphosphorylated RB (pRB) are indicated. $(D)$ SE $\Delta$ does not disrupt the nuclear tethering of RB. Saos-2 cells were cotransfected with full-length RB and either SE $\Delta$ (lanes 3,4) or cyclin A (lanes 5,6). Forty-eight hours post-transfection, cells were fractionated into cytoplasmic (C) and nuclear (N) fractions by use of the low-salt procedure of Mittnacht et al. (1991). Fractions were immunoprecipitated with anti-RB 851, and bound proteins were analyzed by either anti-RB 245 (top) or anti-RB 851 (bottom) immunoblotting.

Likewise, mutations that inactivate the $\mathrm{A} / \mathrm{B}$ pocket of $\mathrm{RB}$ are not tethered to the nucleus and are unable to suppress growth (Mittnacht and Weinberg 1991; Templeton et al. 1991). It has been hypothesized that the nuclear tether is via protein-protein interactions of $R B$ with one or more nuclear matrix proteins (Mittnacht and Weinberg 1991; Templeton et al. 1991; Mancini et al. 1994). Therefore, it was possible that the dominant-negative mutants were disrupting this nuclear tether and therefore disnupting RB function. To test this, Saos-2 cells were cotransfected with full-length $R B$ and either $\mathrm{SE} \Delta$ or cyclin A (Fig. 8D). Following low-salt fractionation (Mittnacht and Weinberg 1991), the majority of the hypophosphorylated RB was present in the nuclear fraction (cf. lanes 1 and 2). Cotransfection of cyclin A with $\mathrm{RB}$ resulted in multiple hyperphosphorylated forms of $\mathrm{RB}$ that were no longer tightly associated with the nucleus (cf. lanes 5 and 6). However, when the dominantnegative mutant SE $\Delta$ was cotransfected with RB, no change in the nuclear association of RB was detected (lanes 3,4). Therefore, even though SE $\Delta$ inactivates the growth-suppressing function of RB, it does not do so by disrupting the tethering of $\mathrm{RB}$ to the nucleus.
$R B-S E \Delta$ allows cell cycle progression in the presence of full-length unphosphorylated $R B$

Although it was clear that the individual pockets of RB could prevent the formation of $G_{1}$-arrested flat cells /see Fig. 7), the transient flat cell assay did not prove that the cells were now actively cycling. To test this, a colony formation assay was used. Expression of RB in Saos-2 cells has been shown to cause a reduction in the number of stably transfected colonies, as selected by resistance to neomycin (Templeton et al. 1991; Qian et al. 1992; Qin et al. 1992; Hiebert 1993; Zhu et al. 1993). Consistent with previous reports, when we expressed RB in Saos-2 cells, the number of neomycin-resistant colonies was reduced at least 10 -fold relative to the vector alone (Fig. $9 \mathrm{~A}$, cf. $-1+$ top plates). However, coexpression with SE or SE $\Delta$ brought the number of neomycin-resistant colonies back to a level similar to that obtained without RB (Fig. 9A). This indicated that the dominant-negative fragments that were capable of reverting the $G_{1}$-arrested flat cell phenotype were also able to reverse the RB-mediated inhibition of colony formation (Fig. 9A). Again, the RB fragment ME had no effect, being unable to reverse the 
A

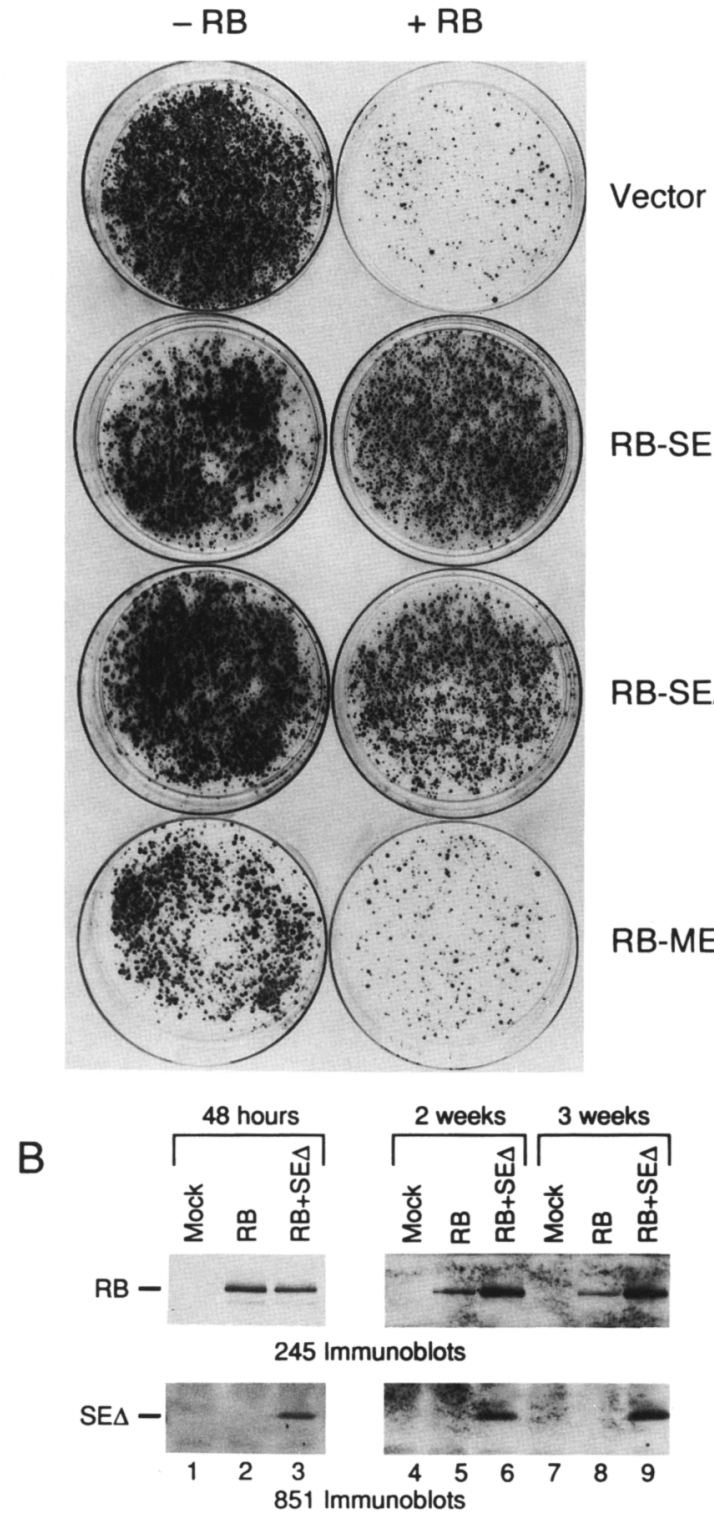

Figure 9. The dominant-negative mutants allow Saos- 2 cell growth in the presence of full-length RB. (A) The dominantnegative mutants prevent $\mathrm{RB}$ from reducing the number of neomycin-resistant Saos- 2 colonies. Saos- 2 cells $\left(2 \times 10^{6}\right)$ were transfected with $\mathrm{pCMV}$ empty vector $(-\mathrm{RB}$, left $)$ or $\mathrm{pCMV}-\mathrm{RB}$ $(+\mathrm{RB}$, right $)$. Both plasmids also carry the neomycin-resistance gene. Certain plates were cotransfected with RB dominant-negative fragments SE, SE $\Delta$, or ME. Cells were selected in G418 $\{500 \mu \mathrm{g} / \mathrm{ml})$ for 14 days and then stained with crystal violet. $(B)$ Full-length RB is present in actively growing Saos- 2 cells expressing SE $\Delta$. Saos- 2 cells $\left(2 \times 10^{6}\right)$ were cotransfected with pCMV-RB and SE $\Delta$ and selected in G418. At the indicated times post-transfection, each plate was lysed in $1 \mathrm{ml}$ and equal lysate volumes were immunoprecipitated with anti-RB 851 . Following immunoprecipitation, the bound proteins were analyzed by either anti-RB 245 (top) or anti-RB 851 (bottom) immunoblotting.

RB-dependent reduction in neomycin-resistant colonies (bottom plates). It is noteworthy that none of the domi- nant-negative mutants had any growth-promoting properties of their own in Saos-2 cells (left row of plates) and therefore appeared to be promoting colony formation by countering the inhibitory activity of RB.

To rule out the possibility that the expression of fulllength $\mathrm{RB}$ was somehow extinguished in these neomycin-resistant colonies, we examined the level of fulllength RB in the stably transfected cells (Fig. 9B). Transfected Saos-2 cells were cultured in neomycin-containing media and harvested at $48 \mathrm{hr}$, or 2 or 3 weeks. Forty-eight hours after transfection, similar levels of fulllength $\mathrm{RB}$ were detected in both the RB- and the $\mathrm{RB}+\mathrm{SE} \Delta$-transfected cells (Fig. 9B, lanes 2,3, top). After the cells were subjected to G418 selection for 2 weeks, the level of full-length RB increased in the cells containing RB and SE $\Delta$ (cf. lanes 5 and 6), proportional to an increase in cell number. This indicated that the cells expressing $\mathrm{RB}$ and $\mathrm{SE} \Delta$ were dividing, thus giving rise to an increase in the level of full-length RB. After 2 weeks in selection, plates were split 1:3 and grown for an additional week in selection. At this 3-week time point, the number of $G_{1}$-arrested flat cells in the RB transfection had decreased noticeably, and a concomitant decrease in full-length RB was observed (cf. lanes 5 and 8). Conversely, cells expressing RB and SE $\Delta$ continued to grow in the presence of full-length $\mathrm{RB}$, even after 3 weeks in selection (cf. lanes 6 and 9). These data allowed us to conclude that the dominant-negative mutants could prevent RB-dependent $G_{1}$ arrest and could activate cell cycle progression even in the presence of full-length, unphosphorylated RB.

\section{Discussion}

The $\mathrm{RB}$ protein is shown to assemble protein complexes by simultaneously binding either E2F and c-Abl (Fig. 2) or cyclin D2 and c-Abl (Fig. 5). The E2F-RB-Abl complex is found in cell lysates and can be assembled in vitro with purified proteins. Formation of this complex is mediated by the previously defined large $\mathrm{A} / \mathrm{B}$ and $\mathrm{C}$ pockets of RB (Figs. 2 and 3). A fragment, RB-SE $\Delta$, containing only the $\mathrm{C}$ pocket, can function as dominant-negative inhibitor of the growth-suppressing function of RB (Figs. 7 and 91. Coexpression of RB with SE $\Delta$ does not lead to activation of E2F or c-Abl tyrosine kinase, does not affect the tethering of RB to the nucleus, and does not induce RB phosphorylation (Figs. 8 and 9). However, overproduction of SE $\Delta$ does compete with the full-length RB for binding to the c-Abl tyrosine kinase (Fig. 8), thus leading to the disruption of RB-assembled complexes. These results strongly suggest that the RB-mediated growth suppression not only depends on the inhibition of its target proteins but also on the ability of RB to properly assemble specific protein complexes.

\section{Redefining the protein-binding domains of $R B$}

Stable interaction of RB with E2F heterodimers on DNA has been shown to require the $\mathrm{A} / \mathrm{B}$ pocket plus carboxy- 
terminal amino acids up to residue 869 , whereas the A/B pocket alone is sufficient to bind E2F-1 protein (Huang et al. 1992; Qian et al. 1992; Qin et al. 1992; Hiebert 1993). Although RB has a nonspecific DNA-binding activity (Lee et al. 1987), it does not make detectable contact with the E2F DNA (Huber et al. 1994). Deletion of RB amino acids 785-806 has been shown previously to abolish the formation of the RB-E2F-DNA complex (Hiebert 1993). In keeping with that observation, we have shown that the RB-SE fragment (amino acids 768-928) could disrupt the RB-E2F-DNA complex, but the SE $\Delta$ fragment, lacking amino acids 785-806, could not. These results suggest that specific carboxy-terminal amino acids are required for $\mathrm{RB}$ to interact with the functional heterodimer of E2F on DNA. The interaction of RB with the D-type cyclins also requires both the A/B pocket and the carboxy-terminal region (Dowdy et al. 1993; Ewen et al. 1993). The observation that the SE and SE $\Delta$ fragments were unable to disrupt the RB-D2 interaction (Fig. 5) suggests that no specific amino acids in the carboxyterminal region are required for binding to D2. Moreover, another A/B pocket-containing protein, p107, also binds the D-type cyclins, despite a very limited sequence identity between RB and p107 in the carboxy-terminal region (Ewen et al. 1991, 1993). It appears that the carboxyterminal region may make some structural contribution but does not play a direct role in binding the D-type cyclins.

The carboxy-terminal region also has a protein-binding domain of its own, that is, the $\mathrm{C}$ pocket that interacts with the c-Abl tyrosine kinase (Welch and Wang 1993). The $\mathrm{C}$ pocket is located entirely within the carboxy-terminal region, between amino acids 768 and 869 /see Fig. 1). Unlike the A/B pocket, the $C$ pocket is not conserved because p 107 is unable to interact with c-Abl (P.J. Welch and J.Y.J. Wang, unpubl.). We have shown here that the large A/B pocket, involved in the formation of RB-E2FDNA or RB-D2 complexes, does not overlap with the C pocket because RB can bind simultaneously to $\mathrm{Abl}$ and either E2F-DNA or cyclin D2. Moreover, an RB mutant $(\Delta 785-806)$, which has lost the ability to bind E2F-DNA, is still capable of interacting with c-Abl. Taken together, the current data suggest that $\mathrm{RB}$ can interact with its targets through several different mechanisms. The A/B pocket function of RB can be augmented by the carboxyterminal amino acids in different ways. The $\mathrm{C}$ pocket, as defined by the binding to $\mathrm{c}-\mathrm{Abl}$ tyrosine kinase, is structurally and functionally distinct from the large $A / B$ pocket. The amino-terminal region of $\mathrm{RB}$ may also possess one or more protein-binding domains (Wang et al. 1994). The presence of multiple protein-binding pockets strongly suggests that one of the functions of $\mathrm{RB}$ is to assemble protein complexes.

\section{Does $R B$ have a positive function?}

It has been suggested that RB suppresses cell growth by inhibiting $G_{1} / S$ progression. $R B$ can inhibit a subset of E2F proteins that are important for the transcription of genes essential to DNA synthesis, for example, DHFR
(Nevins 1992). Interestingly, however, RB has been shown to be essential for the expression of a cell cycle activator, cyclin D1 (Müller et al. 1994). Although the biological significance and the mechanism of this is not known, the observation does suggest that RB can have a net positive effect on gene expression. Our finding that the SE $\Delta$ fragment can overcome RB-mediated growth arrest indicates further that $\mathrm{RB}$ is not merely an inhibitor. Because SE $\Delta$ does not interfere with RB-mediated inhibition of either E2F or C-Abl, but does prevent RB from inhibiting cell proliferation, it is possible that the growth-suppression function of $R B$ involves mechanisms other than a block of the $G_{1} / S$ transition. The protein assembly function of $\mathrm{RB}$ may actively promote cell cycle exit and/or the establishment of quiescence or senescence, and SE $\Delta$ may be disrupting those activities of RB. The RB-arrested Saos-2 flat cells have been described to resemble senescent cells (Templeton et al. 1991). It remains to be determined whether overexpression of SE $\Delta$ would prevent normal cells from entering quiescence or senescence.

\section{$R B$ as a cell-cycle regulated molecular matchmaker}

The hypothesis that RB functions as a molecular matchmaker, bringing together two or more proteins that would otherwise not interact, is appealing for at least two reasons. First, RB is shown to bind a large number of cellular proteins of diverse function (Wang et al. 1994). The matchmaker model does not require RB to be a stoichiometric inhibitor of any of its targets. If the key function of RB is to supervise the formation of protein complexes, it would make sense for RB to have the capability of binding many proteins. Second, the biological function of RB appears to be influenced by the cell context. Homozygous mutation of $R b$ induces retinoblastoma in humans and pituitary tumors in mice. In addition, particular cell types, namely erythrocytes and neurons, appear unable to properly differentiate in the $R b$ knockout mice (for reviews, see Hamel et al. 1993; Wang et al. 1994). The matchmaker model predicts that RB may assemble different protein complexes in different cell types, depending on the expression of $\mathrm{RB}$-binding proteins. A cell type-specific RB-binding protein has been described, for example, the T-cell specific Elf-1 transcription factor, which binds the RB A/B pocket (Wang et al. 1993). Because the combinatorial possibilities of RB-assembled complexes is cell type dependent, the matchmaker model could account for the modulation of $\mathrm{RB}$ function by the cell context.

If $\mathrm{RB}$ can assemble protein complexes of multiple combinatorial possibilities, what then determines which complexes are formed in vivo? Because most of the RBbinding proteins also bind DNA, the assembly of RBmediated protein complexes may be determined by specific DNA sequences. That is, RB may follow the instruction of DNA sequences in making matches. This may account for the observation that only a subset of the $\mathrm{RB}-\mathrm{E} 2 \mathrm{~F}$ complexes in cells contain the c-Abl tyrosine kinase. $\mathrm{RB}$ may also recruit nonDNA-binding proteins to 
specific DNA sequences, as dictated by the specific DNA-binding proteins already present on $\mathrm{RB}$ and the overall stability of the resulting complexes. The matchmaker RB may also bring together enzymes and their substrates. For example, some A/B pocket-binding proteins, or their associated proteins, may be substrates of the c-Abl tyrosine kinase. There is some evidence that the D-type cyclins may be tyrosine phosphorylated in vivo (Hall et al. 1993). Alternatively, the D-type cyclins may target $\mathrm{c}-\mathrm{Abl}$, through $\mathrm{RB}$, for phosphorylation by cdk members. At least nine Ser/Thr sites in c-Abl can be phosphorylated by the activated cdc2 kinase (Kipreos and Wang 1990). Furthermore, RB itself is associated with the nuclear matrix, localized in discrete areas of the nucleus (Mittnacht and Weinberg 1991; Alberts et al. 1993; Szekely et al. 1993; Mancini et al. 1994), and therefore may serve to compartmentalize protein complexes to specific areas of the nucleus.

The protein-binding activity of both the $\mathrm{A} / \mathrm{B}$ and $\mathrm{C}$ pockets is regulated in the cell cycle by cdk/cyclin-mediated phosphorylation (for review, see Wang et al. 1994). $\mathrm{RB}$ contains 16 potential cdk phosphorylation sites and at least 7 of them are phosphorylated in vivo. During $S$ and $G_{2}$ phase, several partially phosphorylated forms of RB are observed. With the identification of distinct protein-binding pockets in $\mathrm{RB}$, it has been suggested that the different pockets are regulated by different phosphorylation sites (Wang et al. 1994). It has been shown that specific phosphorylation sites regulate protein-binding to the $C$ pocket, while having no effect on A/B pocket function (E.S. Knudsen and J.Y.J. Wang, in prep.). The partial phosphorylation of $\mathrm{RB}$ at specific sites could be expected to release proteins from one pocket without affecting the other pocket. The phosphorylation of specific sites could be regulated by specific physiological signals, thereby allowing a regulated disruption of the RB-assembled complexes.

The RB-SE $\Delta$ fragment described here should prove to be a useful reagent in probing RB function, regardless of the specific mechanism of its actions. Until now, inactivation of RB has been achieved by the expression of viral oncoproteins. However, because the viral oncoproteins not only target the A/B pocket of RB but also that of p107 and p130, it is difficult to conclusively assign the biological effects of the oncoproteins to that of RB inactivation. The dominant-negative fragment SE $\Delta$, however, contains no homology to either p107 or p130. Moreover, p107 does not bind c-Abl, underscoring the difference between RB and p107 in the carboxy-terminal domain. Because SE $\Delta$ would not be expected to disrupt p107- or p130-mediated complexes, it is a specific inhibitor of RB and could be used to investigate the role of RB in cell-cycle regulation and terminal differentiation.

\section{Materials and methods}

\section{Cell culture}

C33A, a human cervical carcinoma cell line, and Saos-2, a human osteosarcoma cell line (both from American Type Tissue
Collection/ were cultured at $37^{\circ} \mathrm{C}$ in Dulbecco's modified Eagle medium (DMEM) supplemented with $15 \%$ heat-inactivated fetal bovine serum (FBS; HyClone). 3T3 Abl knockout (3T3ø) cells (a gift from D. Baltimore, Rockefeller University, NY) were cultured at $37^{\circ} \mathrm{C}$ in DMEM supplemented with $10 \%$ calf serum. Sf9 insect cells were cultured at $27^{\circ} \mathrm{C}$ in Grace's insect media (GIBCO BRL) supplemented with $10 \%$ FBS.

\section{Transfections and infections}

C33A and Saos-2 cells were transfected by the calcium phosphate method, as described previously (Chen and Okayama 1987). Vectors used were pBK-CMV (Stratagene) containing the Abl constructs, pCMV-Neo-Bam (Baker et al. 1990) containing full-length RB, pFLAG (IBI) containing the RB dominant-negative fragments, $\mathrm{pRC}-\mathrm{CMV}$ containing human cyclin A (Hinds et al. 1992), and pBABE-puro expressing the puromycin resistance gene driven by the SV40 early promoter (Morgenstern and Land 1990). The Abl-TAG construct was described previously (Welch and Wang 1993). Abl-AS2 was constructed by use of the polymerase chain reaction to replace the ATP-binding lobe of $\mathrm{c}-\mathrm{Abl}$ with the corresponding amino acids of c-Src (P.J. Welch and J.Y.J. Wang, in prep.). Unless otherwise indicated, transfections consisted of $15 \mu \mathrm{g}$ of total DNA/100-mm plate, and the molar ratio of RB DNA to Abl DNA was 1:5. For selection, puromycin (Sigma) was used at $1 \mu \mathrm{g} / \mathrm{ml}$, and G418 (GIBCO BRL) was used at $500 \mu \mathrm{g} / \mathrm{ml}$. To fix and stain cells, a $1 \%$ crystal violet solution in $20 \%$ ethanol was used. Chloramphenicol acetyltransferase (CAT) and $\beta$-galactosidase assays were performed as described previously (Welch and Wang 1993).

Sf 9 cells were infected with recombinant baculoviruses containing murine c-Abl type I (Baskaran et al. 1993), human RB (Lin et al. 1991), or human cyclin D2 (a gift from Dr. C. Sherr, St. Jude Children's Hospital, Nashville, TN), as described previously (Baskaran et al. 1993). For metabolic labeling, $48 \mathrm{hr}$ postinfection, cells were washed once with phosphate buffered saline (PBS) and incubated in Grace's insect medium minus methionine (GIBCO BRL) supplemented with $10 \%$ dialyzed FBS (GIBCO BRL) and containing $200 \mu \mathrm{Ci} / \mathrm{ml}$ of $\left[{ }^{35} \mathrm{~S}\right]$ methionine (ICN) at $27^{\circ} \mathrm{C}$ for $4 \mathrm{hr}$.

\section{Immunoprecipitation, immunoblotting, and in vitro binding}

Antibodies used in this study were monoclonal antibodies antiAbl 8E9 (Richardson et al. 1987), anti-TAG 12CA5 (Niman et al. 1983), anti-RB 245, C36, and XZ133 (Pharmingen) and polyclonal antibodies anti-Abl AXS lagainst the XhoI-Sall fragment of murine c-Abl, amino acids 711-933) and anti-RB 851 (against the last 161 amino acids of human RB). Immunoprecipitations and immunoblotting were performed as described previously (Welch and Wang 1993).

GST purification and cleavage, detergent-free lysate preparation, in vitro translations and in vitro binding conditions were performed as described previously (Welch and Wang 1993), as was biochemical fractionation (Mittnacht and Weinberg 1991). $\mathrm{Abl}$ autophosphorylation activity was measured as described previously (Welch and Wang 1993).

\section{E2F electrophoretic mobility retardation assay}

E2F electrophoretic retardation were performed with ${ }^{32} \mathrm{P}$-endlabeled double-stranded E2F DNA probes, as described (Ikeda and Nevins 1993). E2F, purified from exponentially growing HeLa cells by affinity chromatography, was a gift from Dr. $\mathrm{H}$. Huber (Merck). For typical mobility retardation reactions, $50 \mathrm{ng}$ of GST-RB-Ase/End (RB amino acids 384-928), purified from 
bacteria, was pre-incubated with $150 \mathrm{ng}$ of $\mathrm{c}-\mathrm{Abl}$, purified from baculovirus-infected insect cells in E2F mobility shift buffer (20 mM HEPES at $\mathrm{pH} 7.8,40 \mathrm{~mm} \mathrm{KCl}, 1 \mathrm{~mm} \mathrm{MgCl}_{2}, 0.1 \mathrm{~mm}$ EGTA, $1 \mathrm{mM}$ DTT, $10 \%$ glycerol, $1 \mathrm{ng} / \mu \mathrm{l}$ of sonicated salmon sperm DNA, and $0.5 \mathrm{mg} / \mathrm{ml}$ of BSA), for $30 \mathrm{~min}$ on ice. Then, purified E2F (1:500 dilution) and the radiolabeled probe were added and incubated $20 \mathrm{~min}$ at room temperature followed by $20 \mathrm{~min}$ on ice before being loaded on $4 \%$ polyacrylamide gels (acrylamide/ bisacrylamide, 55:1), $1 \times$ TBE (50 mM Tris base, $50 \mathrm{~mm}$ boric acid, and $1 \mathrm{~mm}$ EGTA). Gels also contained $5 \%$ glycerol to increase the resolution. The gels were run in $1 \times \mathrm{TBE}$ at $4^{\circ} \mathrm{C}$ at 300 $\mathrm{V}$. When antibodies or purified competitor protein fragments were used, they were preincubated with c-Abl for $15 \mathrm{~min}$ on ice prior to the addition of GST-RB.

For coimmunoprecipitation of E2F activity, immunoprecipitations were performed as described previously (Welch and Wang 1993). The precipitated proteins were then incubated with $0.8 \%$ DOC in mobility shift buffer (see above) for $20 \mathrm{~min}$ on ice, followed by the addition of Triton X-100 to $1.5 \%$ final. The beads were spun down, and the supernatant was used directly in the E2F mobility retardation assay (for reference, see Mudryi et al. 1991).

\section{Acknowledgments}

We thank Dr. R. Baskaran (University of California, San Diego) for the purified c-Abl protein, Dr. H. Huber (Merck) for the purified E2F, Dr. B. Chang (University of California, San Diego) for the purified anti-Abl AXS antibody, Dr. D. Baltimore (Rockefeller University) for the 3T3ø cells, Dr. Y.-J. Miao for the 3T3ø-Abl-TAG cells, E. Knudsen for the pCMV-Neo-Bam-RB construct, and Dr. C. Sherr (St. Jude Children's Hospital) for the recombinant baculovirus containing human cyclin $\mathrm{D} 2$. We also thank S. Lilgegren for being the first to observe that the internal deletion SE $\Delta 785-806$ was still capable of binding c-Abl. The RB $\Delta 785-806$ construct was a gift from Dr. S. Hiebert (St. Jude Children's Hospital), pBABE-puro was a gift from Dr. H. Land (Imperial Cancer Research Fund, London), E2-CAT was a gift from Dr. E. Harlow (Massachusetts General Hospital), pRC$\mathrm{CMV}$-cyclin A was a gift from Dr. S. Reed (Scripps Research Institute), and pCMV-Neo-Bam was a gift from Dr. B. Vogelstein (Johns Hopkins University). This work was supported by a grant to J.Y.J.W. from the National Institutes of Health (CA58320). P.J.W. is a fellow of the Cancer Research Coordinating Committee at the University of California.

The publication costs of this article were defrayed in part by payment of page charges. This article must therefore be hereby marked "advertisement" in accordance with 18 USC section 1734 solely to indicate this fact.

\section{References}

Alberts, A.S., A.M. Thorburn, S. Shenolikar, M.C. Mumby, and J.R. Feramisco. 1993. Regulation of cell cycle progression and nuclear affinity of the retinoblastoma protein by protein phosphatases. Proc. Natl. Acad. Sci. 90: 388-392.

Baker, S.J., S. Markowitz, E.R. Fearon, J.K. Willson, and B. Vogelstein. 1990. Suppression of human colorectal carcinoma cell growth by wild-type p53. Science 249: 912-915.

Baskaran, R., M.E. Dahmus, and J.Y.J. Wang. 1993. Tyrosine phosphorylation of mammalian RNA polymerase II carboxylterminal domain. Proc. Natl. Acad. Sci. 90: 11167-11171.

Bookstein, R., J.-Y. Shew, P.-L. Chen, P. Scully, and W.-H. Lee. 1990. Suppression of tumorigenicity of human prostate carcinoma cells by replacing a mutated RB gene. Science 247: 712-715.
Chellappan, S.P., S. Hiebert, M. Mudryj, J.M. Horowitz, and J.R. Nevins. 1991. The E2F transcription factor is a cellular factor for the RB protein. Cell 65: 1053-1061.

Chen, C.A. and H. Okayama. 1987. High efficiency transformation of mammalian cells by plasmid DNA. Mol. Cell. Biol. 7: 2745-2752.

Clarke, A.R., E.R. Maandag, M. van Roon, N.M.T. van der Lugt, M. van der Valk, M.L. Hooper, A. Berns, and H. te Riele. 1992. Requirement for a functional $R b-1$ gene in murine development. Nature 359: 328-330.

Cobrinik, D., P. Whyte, D.S. Peeper, T. Jacks, and R.A. Weinberg. 1993. Cell cycle-specific association of E2F with the p130 E1A-binding protein. Genes \& Dev. 7: 2392-2404.

Dahmus, M.E. and W.S. Dynan. 1992. Phosphorylation of RNA polymerase II as a transcriptional regulatory mechanism. In Transcriptional regulation (ed. S.L. McKnight and K.R. Yamamoto|, pp. 109-128. Cold Spring Harbor Laboratory Press, Cold Spring Harbor, New York.

DeCaprio, J.A., J.W. Ludlow, J. Figge, J.-Y. Shew, C.-M. Huang, W.-H. Lee, E. Marsilio, E. Paucha, and D.M. Livingston. 1988. SV40 large $T$ antigen forms a specific complex with the product of the retinoblastoma susceptibility gene. Cell 54: 275-283.

Dowdy, S.F., P.W. Hinds, K. Louie, S.I. Reed, A. Arnold, and R.A. Weinberg. 1993. Physical interaction of the retinoblastoma protein with human D cyclins. Cell 73: 499-511.

Duyster, J., R. Baskaran, and J.Y.J. Wang. 1995. SH2 domain as a specificity determinant in the c-Abl mediated tyrosine phosphorylation of RNA polymerase II-CTD. Proc. Natl. Acad. Sci. (in press).

Dyson, N., P.M. Howley, K. Munger, and E. Harlow. 1989. The human papilloma virus-16 E7 oncoprotein is able to bind the retinoblastoma gene product. Science 243: 934-936.

Ewen, M.E., Y. Xing, J.B. Lawrence, and D.M. Livingston. 1991. Molecular cloning, chromosomal mapping, and expression of the cDNA for p107, a retinoblastoma gene product-related protein. Cell 66: 1155-1164.

Ewen, M.E., H.K. Sluss, C.J. Sherr, H. Matsushime, J.-Y. Kato, and D.M. Livingston. 1993. Functional interactions of the retinoblastoma protein with mammalian D-type cyclins. Cell 73: 487-497.

Feller, S.M., B. Knudsen, and H. Hanafusa. 1994. c-Abl kinase regulates the protein binding activity of c-Crk. EMBO I. 13: 2341-2351.

Flemington, E.K., S.H. Speck, and W.G. Kaelin, Jr. 1993. E2F-1mediated transactivation is inhibited by complex formation with the retinoblastoma suceptibility gene product. Proc. Natl. Acad. Sci. 90: 6914-6918.

Fung, Y.-K.T., A. T'Ang, A.L. Murphree, F.H. Zhang, W.R. Qiu, S.W. Wang, X.H. Shi, L. Lee, B. Driscoll, and K.J. Wu. 1993. $\mathrm{The} \mathrm{Rb}$ gene suppresses the growth of normal cells. Oncogene 8: 2659-2672.

Hall, F.L., R.T. Williams, L. Wu, F. Wu, D.A. Carbonaro-Hall, J.W. Harper, and D. Warburton. 1993. Two potentially oncogenic cyclins, cyclin A and cyclin D1, share common properties of subunit configuration, tyrosine phosphorylation and physical association with the $\mathrm{RB}$ protein. Oncogene 8: 1377-84.

Hamel, P.A., R.A. Phillips, M. Muncaster, and B.L. Gallie. 1993. Speculations on the roles of $R B 1$ in tissue-specific differentiation, tumor initiation and tumor progression. FASEB $I$. 7: 846-854.

Hansen, M.F., R. Morgan, A.A. Sandberg, and W.K. Cavenee. 1990. Structural alterations at the putative retinoblastoma locus in some human leukemias and preleukemia. Cancer Genet. Cytogenet. 49: 15-23. 
Helin, K., J.A. Lees, M. Vidal, N. Dyson, E. Harlow, and A. Fattaey. 1992. A cDNA encoding a pRB-binding protein with properties of the transcription factor E2F. Cell 70: 337-350.

Helin, K., E. Harlow, and A. Fattaey. 1993. Inhibition of E2F-1 transactivation by direct binding of the retinoblastoma protein. Mol. Cell. Biol. 13: 6501-6508.

Hiebert, S.W. 1993. Regions of the retinoblastoma gene product required for its interaction with the E2F transcription factor are necessary for E2 promoter repressin and pRB-mediated growth suppression. Mol. Cell. Biol. 13: 3384-3391.

Hiebert, S.W., S.P. Chellappan, J.M. Horowitz, and J.R. Nevins. 1992. The interaction of RB with E2F coincides with an inhibition of the transcriptional activity of E2F. Genes \& Dev. 6: 177-185.

Hinds, P.W., S. Mittnacht, V. Dulic, A. Arnold, S.I. Reed, and R.A. Weinberg. 1992. Regulation of retinoblastoma protein functions by ectopic expression of human cyclins. Cell 70: 993-1006.

Howes, K.A., N. Ransom, D.S. Papermaster, J.G.H. Lasudry, D.M. Albert, and J.J. Windle. 1994. Apoptosis or retinoblastoma: Alternative fates of photoreceptors expressing the HPV-16 E7 gene in the presence or absence of p53. Genes \& Dev. 8: 1300-1310.

Hu, Q., N. Dyson, and E. Harlow. 1990. The regions of the retinoblastoma protein needed for binding to adenovirus E1A or SV40 large $T$ antigen are common sites for mutations. EMBO I. 9: 1147-1155.

Huang, H.-J.S., J.-K. Yee, J.-Y. Shew, P.-L. Chen, R. Bookstein, T. Friedmann, E.Y.-H.P. Lee, and W.-H. Lee. 1988. Suppression of the neoplastic phenotype by replacement of the RB gene in human cancer cells. Science 242: 1563-1566.

Huang, P.S., D.R. Patrick, G. Edwards, P.J. Goodhart, H.E. Huber, L. Miles, V.M. Garsky, A. Oliff, and D.C. Heimbrook. 1993. Protein domains governing interactions between E2F, the retinoblastoma gene product, and human papillomavirus type 16 E7 protein. Mol. Cell. Biol. 13: 953-960.

Huang, S., E. Shin, K.-A. Sheppard, L. Chokroverty, B. Shan, Y.-W. Qian, E.Y.-H.P. Lee, and A.S. Yee. 1992. The retinoblastoma protein region required for interaction with the E2F transcription factor includes the T/E1A binding and carboxy-terminal sequences. DNA Cell Biol. 11: 539-548.

Huber, H.E., P.J. Goodhart, and P.S. Huang. 1994. Retinoblastoma protein reverses DNA bending by transcription factor E2F. J. Biol. Chem. 269: 6999-7005.

Ikeda, M.-A. and J.R. Nevins. 1993. Identification of distinct roles for separate E1A domains in disruption of E2F complexes. Mol. Cell. Biol. 13: 7029-7035.

Jacks, T., A. Fazeli, E.M. Schmitt, R.T. Bronson, M.A. Goodell, and R.A. Weinberg. 1992. Effects on an $R b$ mutation in the mouse. Nature 359: 295-300.

Kaelin, W.G., Jr., M.E. Ewen, and D.M. Livingston. 1990. Definition of the minimal simian virus 40 large $T$ antigen- and adenovirus E1A-binding domain in the retinoblastoma gene product. Mol. Cell. Biol. 10: 3761-3769.

Kaelin, W.G., W. Krek, W.R. Sellers, J.A. DeCaprio, F. Ajchenbaum, C.S. Fuchs, T. Chittenden, Y. Li, P.J. Farnham, M.A. Blanar, D.M. Livingston, and E.K. Flemington. 1992. Expression cloning of a cDNA encoding a retinoblastoma-binding protein with E2F-like properties. Cell 70: 351-364.

Kato, J.-Y., H. Matsushime, S.W. Hiebert, M.E. Ewen, and C.J. Sherr. 1993. Direct binding of cyclin D to the retinoblastoma gene product $(\mathrm{pRb})$ and $\mathrm{pRb}$ phosphorylation by the cyclin D-dependent kinase CDK4. Genes \& Dev. 7: 331-342.

Kipreos, E.T. and J.Y.J. Wang. 1990. Differential phosphorylation of c-Abl in cell cycle determined by cdc2 kinase and phosphatase activity. Science 248: 217-220.
- 1992. cell cycle-regulated binding of c-Abl tyrosine kinase to DNA. Science 256: 382-385.

Lee, E.Y.-H.P., C.-Y. Chang, N. Hu, Y.-C.J. Wang, C.-C. Lai, K. Herrup, W.-H. Lee, and A. Bradley. 1992. Mice deficient for $\mathrm{Rb}$ are nonviable and show defects in neurogenesis and haematopoiesis. Nature 359: 288-294.

Lee, W.-H., J.-Y. Shew, F.D. Hong, T.W. Sery, L.A. Donoso, L.-J. Young, R. Bookstein, and E.Y.-H.P. Lee. 1987. The retinoblastoma susceptibility gene encodes a nuclear phosphoprotein associated with DNA-binding activity. Nature 329: 642-645.

Lin, B.T.-Y., S. Gruenwald, A.O. Morla, W.-H. Lee, and J.Y.J. Wang. 1991. Retinoblastoma cancer suppressor gene product is a substrate of the cell cycle regulator cdc2 kinase. $E M B O$ I. 10: $857-864$.

Mancini, M.A., B. Shan, J.A. Nickerson, S. Penman, and W.H. Lee. 1994. The retinoblastoma gene product is a cell cycledependent, nuclear matrix-associated protein. Proc. Natl. Acad. Sci. 91: 418-422.

Mittnacht, S. and R.A. Weinberg. 1991. G1/S phosphorylation of the retinoblastoma protein is associated with an altered affinity for the nuclear compartment. Cell 65: 381-393.

Mittnacht, S., J.A. Lees, D. Desai, E. Harlow, D.O. Morgan, and R.A. Weinberg. 1994. Distinct sub-populations of the retinoblastoma protein show a distinct pattern of phosphorylation. $E M B O$ J. 13: 118-127.

Morgenstern, J.P. and H. Land. 1990. Advanced mammalian gene transfer: High titer retroviral vectors with multiple drug selection markers and a complementary helper-free packaging cell line. Nucleic Acid. Res. 18: 3587-3596.

Mudryi, M., S.H. Devoto, S.W. Hiebert, T. Hunter, J. Pines, and J.R. Nevins. 1991. Cell cycle regulation of the E2F transcription factor involves an interaction with cyclin A. Cell 65: 1243-1253.

Müller, H., J. Lukas, A. Schneider, P. Warthoe, J. Bartek, M. Eilers, and M. Strauss. 1994. Cyclin Dl expression is regulated by the retinoblastoma protein. Proc. Natl. Acad. Sci. 91: 2945-2949.

Nevins, J.R. 1992. E2F: A link between the RB tumor-suppressor protein and viral oncoproteins. Science 258: 424-429.

Niman, H.L., R.A. Houghten, L.E. Walker, R.A. Reisfeld, I.A. Wilson, J.M. Hogle, and R.A. Lerner. 1983. Generation of protein-reactive antibodies by short peptides is an event of high frequency: Implications for the structural basis of immune recognition. Proc. Natl. Acad. Sci. 80: 4949-4953.

Pan, H. and A.E. Griep. 1994. Altered cell cycle regulation in the lens of HPV-16 E6 or E7 transgenic mice: Implications for tumor-suppressor gene function in development. Genes \& Dev. 8: 1285-1299.

Phelps, W.C., K. Munger, C.L. Yee, J.A. Barnes, and P.M. Howley. 1992. Structure-function analysis of the human papillomavirus type 16 E7 oncoprotein. J. Virol. 66: 2418-2427.

Qian, Y., C. Luckey, L. Horton, M. Esser, and D.J. Templeton. 1992. Biological function of the retinoblastoma protein requires distinct domains for hyperphosphorylation and transcription factor binding. Mol. Cell. Biol. 12: 5363-5372.

Qin, X.-Q., T. Chittenden, D.M. Livingston, and W.G. Kaelin, Jr. 1992. Identification of a growth suppression domain within the retinoblastoma gene product. Genes \& Dev. 6: 953-964.

Ren, R.B., Z.S. Ye, and D. Baltimore. 1994. Abl protein-tyrosine kinase selects the Crk adapter as a substrate using SH3-binding sites. Genes \& Dev. 8: 783-795.

Richardson, J.M., A.O. Morla, and J.Y.J. Wang. 1987. Reduction in protein tyrosine phosphorylation during differentiation of human leukemia cell line K562. Cancer Res. 47: 4066-4070.

Szekely, L., P. Jin, W.-Q. Jiang, A. Rosén, K.G. Wiman, G. Klein, 
and N. Ringertz. 1993. Position-dependent nuclear accumulation of the retinoblastoma (RB) protein during in vitro myogenesis. J. Cell. Physiol. 155: 313-322.

Templeton, D.J. 1992. Nuclear binding of purified retinoblastoma gene product is determined by cell cycle-regulated phosphoryation. Mol. Cell. Biol. 12: 435-443.

Templeton, D.J., S.H. Park, L. Lanier, and R.A. Weinberg. 1991. Nonfunctional mutants of the retinobastoma protein are characterized by defects in phosphorylation, viral oncoprotein association and nuclear tethering. Proc. Natl. Acad. Sci. 88: 3033-3037.

Tybulewicz, V.L.J., C.E. Crawford, P.K. Jackson, R.T. Bronson, and R.C. Mulligan. 1991. Neonatal lethality and lymphopenia in mice with a homozygous disruption of the c-abl protooncogene. Cell 65: 1153-1 163.

Wang, C.-Y., B. Petryniak, C.B. Thompson, W.G. Kaelin, and J.M. Leiden. 1993. Regulation of the Ets-related transcription factor Elf- 1 by binding to the retinoblastoma protein. Science 260: 1330-1335.

Wang, J.Y.J. 1993. Abl tyrosine kinase in signal transduction and cell-cycle regulation. Curr. Opin. Genet. Dev. 3: 35-43.

. 1994. Nuclear protein tyrosine kinases. Trends Biochem. Sci. 19: 373-376.

Wang, J.Y.J., E.S. Knudsen, and P.J. Welch. 1994. The retinoblastoma tumor-suppressor protein. Adv. Cancer Res. 64: 25-85.

Weintraub, S.J., C.A. Prater, and D.C. Dean. 1992. Retinoblastoma protein switches the E2F site from positive to negative element. Nature 358: 259-261.

Welch, P.J. and J.Y.J. Wang. 1993. A C-terminal protein binding domain in $\mathrm{RB}$ regulates the nuclear $\mathrm{C}-\mathrm{Abl}$ tyrosine kinase in the cell cycle. Cell 75: 779-790.

Whyte, P., K.J. Buchkovich, J.M. Horowitz, S.H. Friend, M. Raybuck, R.A. Weinberg, and E. Harlow. 1988. Association between an oncogene and an anti-oncogene: The adenovirus ElA proteins bind to the retinoblastoma gene product. $\mathrm{Na}$ ture 334: 124-129.

Wu, E.W., K.E. Clemens, D.V. Heck, and K. Münger. 1993. The human papillomavirus E7 oncoprotein and the cellular transcription factor E2F bind to separate sites on the retinoblastoma tumor-suppressor protein. J. Virol. 67: 2402-2407.

Zacksenhaus, E., R. Bremner, R.A. Phillips, and B.L. Gallie. 1993. A bipartite nuclear localization signal in the retinoblastoma gene product and its importance for biological activity. Mol. Cell. Biol. 13: 4588-4599.

Zhu, L., S. van den Heuvel, K. Helin, A. Fattaey, M. Ewen, D. Livingston, N. Dyson, and E. Harlow. 1993. Inhibition of cell proliferation by $\mathrm{p} 107$, a relative of the retinoblastoma protein. Genes \& Dev. 7: 1111-1125. 


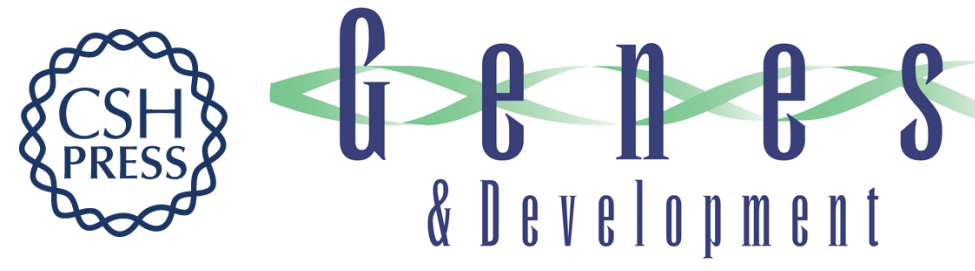

\section{Disruption of retinoblastoma protein function by coexpression of its C pocket fragment.}

$P \mathrm{~J}$ Welch and $\mathrm{J} Y$ Wang

Genes Dev. 1995, 9:

Access the most recent version at doi:10.1101/gad.9.1.31

References This article cites 68 articles, 36 of which can be accessed free at:

http://genesdev.cshlp.org/content/9/1/31.full.html\#ref-list-1

License

Email Alerting

Service

Receive free email alerts when new articles cite this article - sign up in the box at the top right corner of the article or click here.

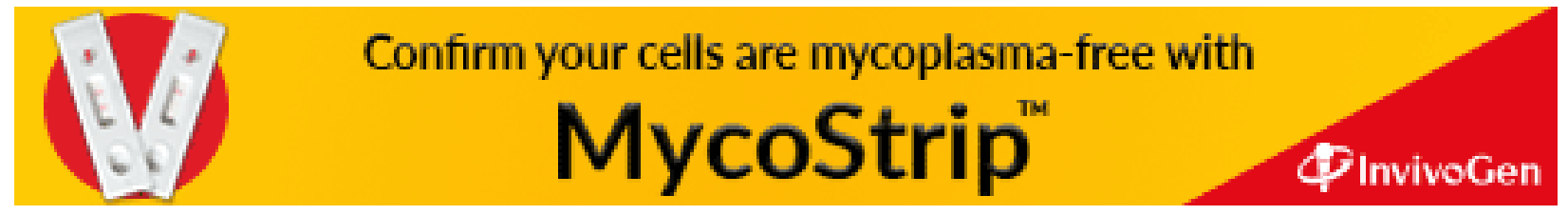

